\title{
Clinical Assessment and Management of Delirium in the Palliative Care Setting
}

\author{
Shirley Harvey Bush ${ }^{1,2,3,4} \cdot$ Sallyanne Tierney ${ }^{4}$ Peter Gerard Lawlor ${ }^{1,2,3,4}$
}

Published online: 1 September 2017

(c) The Author(s) 2017. This article is an open access publication

\begin{abstract}
Delirium is a neurocognitive syndrome arising from acute global brain dysfunction, and is prevalent in up to $42 \%$ of patients admitted to palliative care inpatient units. The symptoms of delirium and its associated communicative impediment invariably generate high levels of patient and family distress. Furthermore, delirium is associated with significant patient morbidity and increased mortality in many patient populations, especially palliative care where refractory delirium is common in the dying phase. As the clinical diagnosis of delirium is frequently missed by the healthcare team, the case for regular screening is arguably very compelling. Depending on its precipitating factors, a delirium episode is often reversible, especially in the earlier stages of a life-threatening illness. Until recently, antipsychotics have played a pivotal role in delirium management, but this role now requires critical reevaluation in light of recent research that failed to demonstrate their efficacy in mild- to moderate-severity delirium occurring in palliative care patients. Non-pharmacological strategies for the management of delirium play
\end{abstract}

Electronic supplementary material The online version of this article (doi:10.1007/s40265-017-0804-3) contains supplementary material, which is available to authorized users.

Shirley Harvey Bush

sbush@bruyere.org

1 Department of Medicine, University of Ottawa, Ottawa, ON, Canada

2 Bruyère Research Institute (BRI), Ottawa, ON, Canada

3 Ottawa Hospital Research Institute (OHRI), Ottawa, ON, Canada

4 Bruyère Continuing Care, 43 Bruyère Street, Ottawa, ON K1N 5C8, Canada a fundamental role and should be optimized through the collective efforts of the whole interprofessional team. Refractory agitated delirium in the last days or weeks of life may require the use of pharmacological sedation to ameliorate the distress of patients, which is invariably juxtaposed with increasing distress of family members. Further evaluation of multicomponent strategies for delirium prevention and treatment in the palliative care patient population is urgently required.

\section{Key Points}

In inpatient palliative care settings, delirium prevalence increases from $13-42 \%$ on admission to $88 \%$ in the last weeks-hours of life. Delirium causes significant morbidity, including increased frequency of falls, increased cognitive and functional impairment, and significant patient and family psychological distress, and is associated with increased mortality.

Although antipsychotics are commonly used in the management of delirium in palliative care patients, recent research evidence in mild- to moderateseverity delirium suggests that antipsychotics are associated with both increased delirium symptoms and reduced patient survival.

While non-pharmacological delirium strategies should intuitively be an integral part of quality patient care, their role in the management of delirium in the palliative care context is unclear; outcome evidence in terms of their effectiveness in this patient population is still required. 


\section{Introduction and Aims}

Delirium is a complex multifactorial syndrome resulting from global organic cerebral dysfunction. The prevalence of delirium is $18-35 \%$ in general medical inpatients and up to $50 \%$ in intensive care patients [1]. In a palliative setting, prevalence is reported as $13-42 \%$ on admission to inpatient palliative care units, increasing to $88 \%$ at the end of life (weeks-hours before death) [2]. Advanced age and dementia are common predisposing risk factors across most healthcare settings, with a $56 \%$ incidence of delirium in patients with dementia [1]. Delirium has many negative consequences, including a strong association with higher morbidity and mortality [3]. It is associated with an increased incidence of falls, longer hospital stays, and greater healthcare costs [1]. Delirium appears to worsen pre-existing dementia as well as increase the risk of 'de novo' dementia [1, 4]. Delirium impairs patient communication, thus challenging symptom assessment in palliative care patients.

The World Health Organization (WHO) defines palliative care as "an approach that improves the quality of life of patients and their families facing the problem associated with life-threatening illness, through the prevention and relief of suffering by means of early identification and impeccable assessment and treatment of pain and other problems, physical, psychosocial and spiritual" [5]. Palliative care is provided by specialists and generalists across various care settings to meet patient needs: specialist inpatient palliative care units (including those in acute care settings and stand-alone inpatient hospices), acute care with hospital consult teams, and community palliative care services. Palliative care is applicable anywhere in a person's illness trajectory, from diagnosis to end of life, and includes bereavement support (see Fig. 1). For the purposes of this paper, unless otherwise specified, we use 'end of life' to mean the presence of progressive life-limiting disease in a patient with a prognosis of weeks-months (as opposed to years), as proposed by Hui et al. [6] in a systematic review of palliative care definitions and concepts and 'dying phase' (viewed as synonymous with terminal phase or actively dying) as "the hours or days preceding imminent death, during which time the patient's physiologic functions wane" [7].

The aim of this review article is to provide a clinically oriented guide to the management of delirium in adult patients in palliative care settings. However, prompt and effective recognition of delirium and its etiologic presentation, together with patient and family-centered, ethical healthcare decision-making, and a preventive approach, are pre-requisites in an effective and comprehensive management plan, and will therefore be addressed.

\subsection{Literature Search}

The systematic literature search to inform this narrative review was conducted in Cochrane, Ovid MEDLINE, EMBASE, and SCOPUS databases from 2006 to 3 January 2017. Search terms included "delirium", "confusion", "palliative", "prevention", "antipsychotic agents", "haloperidol", "alpha adrenergic agents", "cholinesterase inhibitors", "benzodiazepines", "therapeutics", "medications", "drugs", "pharmacology", and "treatment". Results were limited to the English language. All original human clinical trials, systematic reviews, meta-analyses, and clinical practice guidelines were included. All case reports and editorials were excluded, as were papers that focused on alcohol withdrawal delirium (delirium tremens) and pediatric populations.

\section{Clinical Features and Standard Diagnostic Criteria for Delirium}

Although the global cerebral dysfunction associated with delirium is manifested as multiple symptoms and signs, collectively constituting a neurocognitive or neuropsychiatric disorder, the hallmark of delirium is impaired attention. The core clinical criteria for a diagnosis are codified in the American Psychiatric Association's Diagnostic and Statistical Manual of Mental Disorders (DSM), and the fifth edition (DSM-5) [8] updated its itemized diagnostic criteria for delirium. This entailed changing the essential diagnostic feature to "a disturbance in attention and awareness", as compared to "a disturbance of consciousness with reduced ability to focus, sustain or shift attention" in the previous DSM version [fourth edition, text revision (DSM-IV-TR)] [9]. Additionally, delirium is a change from baseline attention and awareness developing over a short period of time (hours-days) with fluctuations in severity over a 24-h time period. Other changes in cognition may also occur. Examples include disorientation, memory deficit, and disturbances in language, visuospatial ability, or perception. Additional clinical features of delirium (that are not part of the core DSM-5 criteria) include sleep-wake cycle disturbance, delusions, dysarthria, dysgraphia, emotional lability, and abnormal psychomotor activity (hypo- or hyperactivity).

In countries other than the USA, the International Classification of Diseases (ICD) classification is frequently used. The ICD-10 criteria overlap with some of the DSM-5 features and also provide additional criteria for disturbances in psychomotor function, sleep-wake cycle, and emotional state [10]. Sleep disturbance (with difficulty falling asleep and frequent awakening leading to sleepless nights) is one of the earliest prodromal symptoms of 


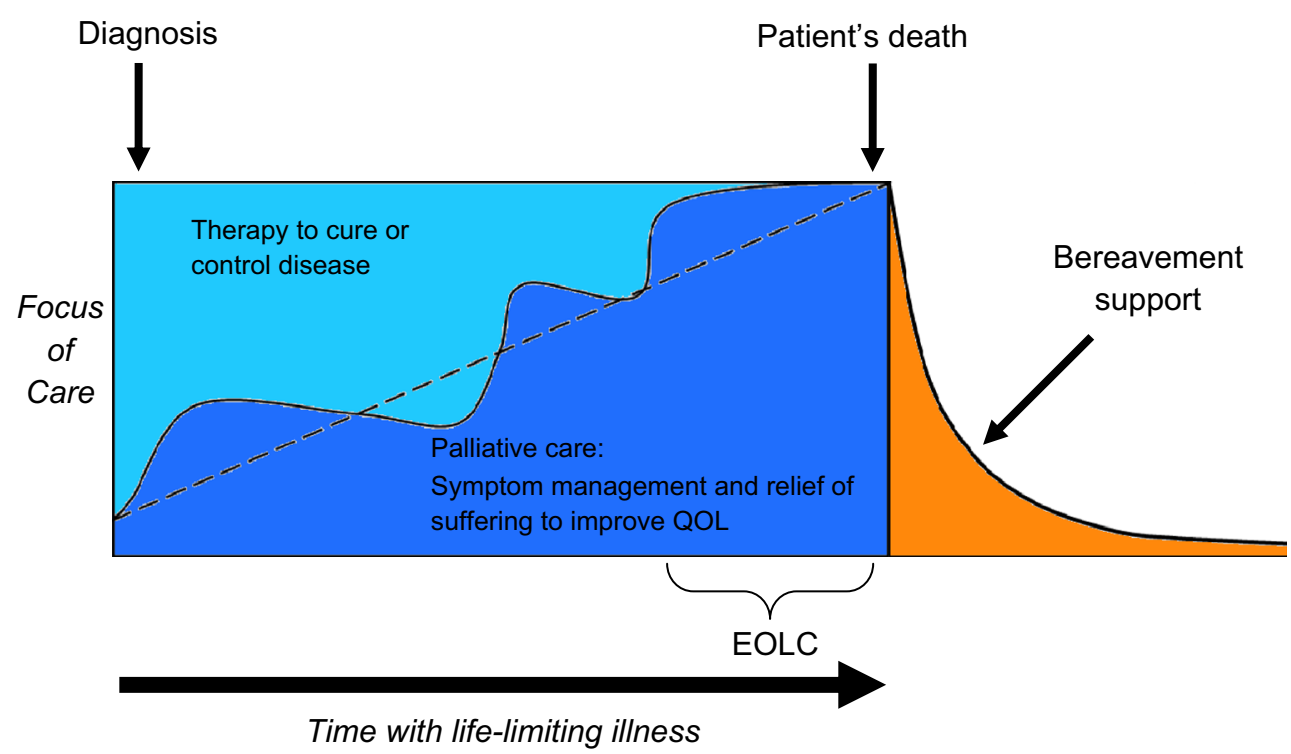

Fig. 1 Model of palliative care throughout trajectory of life-limiting illness (adapted from Canadian Hospice Palliative Care Association [159]). $E O L C$ end-of-life care, $Q O L$ quality of life

delirium [11]. Other prodromal features include irritability, anxiety, and restlessness [11]. Subsyndromal delirium (SSD) has also been described where a person has some but not all of the delirium features and so does not meet the full diagnostic criteria.

\section{Approach to Clinical Assessment of Delirium}

Delirium is a clinical diagnosis that is frequently overlooked or misdiagnosed by the healthcare team $[3,12,13]$. This may be due to lack of recognition of delirium features, overlap with the clinical features of depression and dementia in particular, the occurrence of fluctuating symptom intensity and transient lucidity, and is compounded by inadequate delirium screening or an absence of regular screening [14]. Figure 2 provides an algorithm for the assessment and management of delirium in palliative care.

\subsection{Delirium Screening}

The detection of delirium may be improved by the routine use of observational screening tools by nursing staff and cognitive screening tools or brief tests of attention, such as reciting the months of the years backwards. The choice of clinical tool may in part be determined by the level of staff training required, ease of administration and the potential level of patient, family, and staff burden [15]. It is also extremely useful to obtain a collateral history from a caregiver regarding a person's baseline cognitive function, and for caregivers to report any acute change in mental status to the healthcare team. The Single Question in Delirium (SQiD) asks the patient's family or friend: "Do you feel that [patient's name] has been more confused lately?" [16].

\subsubsection{Confusion Assessment Method (CAM)}

A commonly used screening instrument is the Confusion Assessment Method (CAM) [17]. The full version of the CAM instrument has a total of nine items based on the DSMIII-R criteria. The CAM diagnostic algorithm consists of four items from the full CAM and has been validated in palliative care [18]. In order to identify a CAM-positive delirium, the two essential features of "acute onset and fluctuating course" and "inattention" are required, in addition to "disorganized thinking" or "altered level of consciousness". The CAM is a copyrighted instrument which is available from the website for the Hospital Elder Life Program (HELP) [19]. Formal CAM training is essential to ensure reliability. The CAM was designed to be administered with a brief cognitive assessment tool, such as the Mini-Mental State Examination (MMSE) or Short Orientation Memory Concentration Test (SOMCT) as cognitive disturbance is also a diagnostic criterion for delirium [20,21]. The recently described 3D-CAM operationalizes the CAM using a 3-min assessment [22]. Table 1 shows some commonly used delirium screening tools.

\subsection{Making a Diagnosis of Delirium}

The ideal approach to making the diagnosis of delirium in palliative care is to conduct a clinical interview, obtain a 


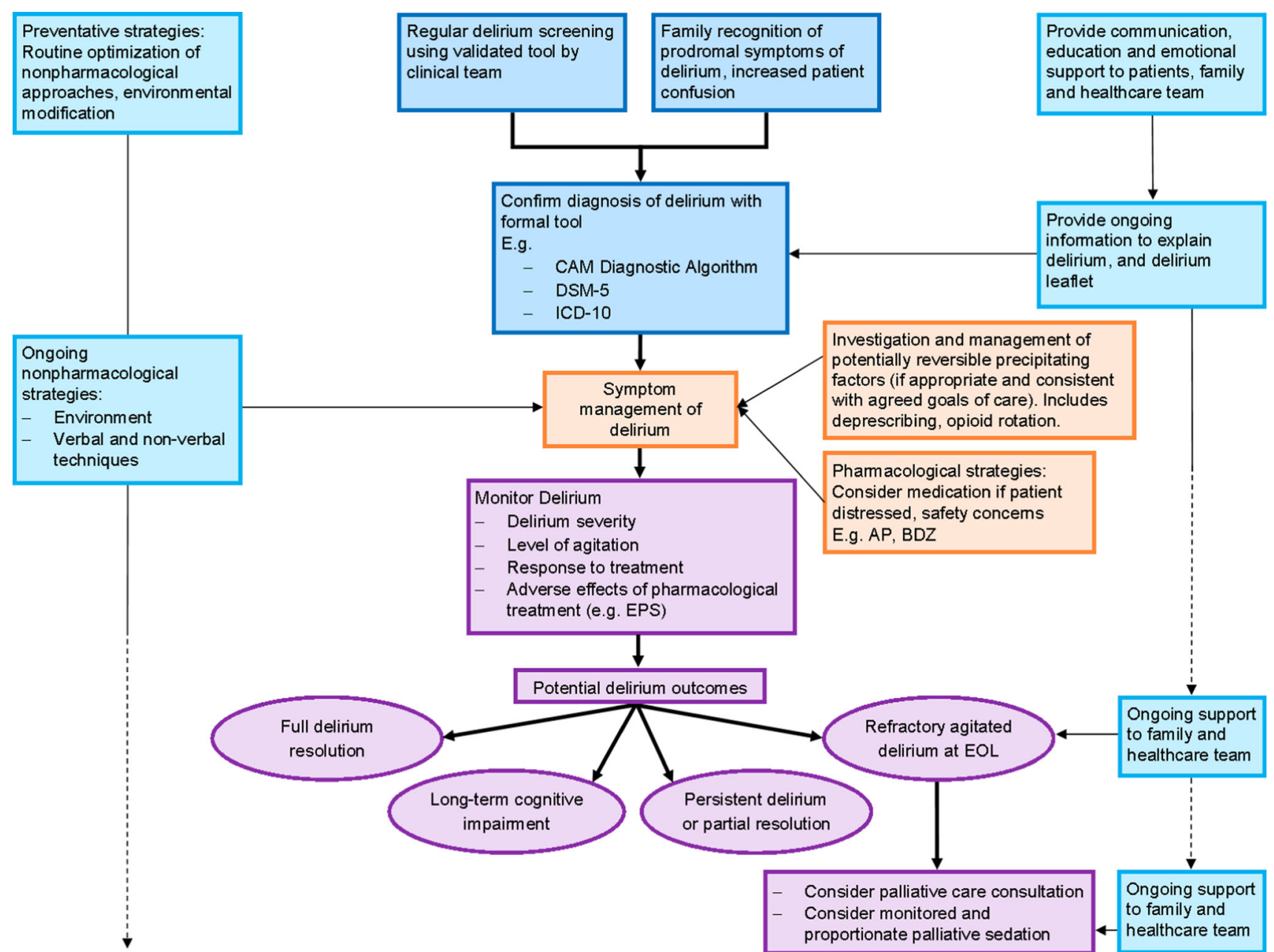

Fig. 2 Algorithm for the assessment and management of delirium in palliative care patients. $A P$ antipsychotic, $B D Z$ benzodiazepine, $C A M$ Confusion Assessment Method, DSM-5 Diagnostic and Statistical

collateral history, and assess the patient's cognition in a systematic manner [25], which together allow the assessor to operationalize the DSM-5 delirium diagnostic criteria. These criteria consist of an attention and awareness disturbance; a temporal acuity of onset (hours-days); an additional cognitive deficit; a requirement that the cognitive disturbance is not better explained by an existing or evolving dementia or a comatose state; and, lastly, that there is evidence from the clinical assessment or investigations to indicate that the disturbance is due to a medical condition, a substance (intoxication or withdrawal), a toxin, or multiple factors [8]. In clinical practice, the CAM is frequently used as a diagnostic tool. To a large degree, the CAM practically operationalizes the DSM-5 criteria for delirium, which is supported by their demonstrated significant agreement [26]. Although this process is often straightforward and effectively administered, this is not always the case.
Manual of Mental Disorders, 5th Edition, EOL end of life, EPS extrapyramidal side effects, $I C D-10$ International Classification of Diseases, 10th revision

Challenges arise in the context of the palliative care setting where the burden of assessment and investigation has to be weighed against the need for thoroughness, especially in the dying phase. Furthermore, co-morbidity levels tend to increase with disease progression, as do levels of frailty, cachexia, fatigue and pain, which collectively add to the challenge of conducting a thorough diagnostic assessment of delirium. The phenomenological overlap between the diagnoses of dementia, delirium and depression warrants consideration and differentiation, especially the attentional deficit and acuity of onset that characterize delirium. The diagnosis of delirium superimposed on dementia is often very challenging and may only be exposed when therapeutic interventions to reverse delirium are only partly effective [27]. Clinicians also need to recognize delirium psychomotor abnormalities in their diagnostic assessments. Examples of delirium assessment tools for diagnosis and severity ratings are shown in Table 2. 
Table 1 Commonly used delirium screening tools [17, 23, 24]

\begin{tabular}{|c|c|c|}
\hline Tool or criteria & Administration & Comments \\
\hline $\begin{array}{l}\text { Confusion Assessment } \\
\text { Method (CAM) }\end{array}$ & $\begin{array}{l}\text { Healthcare team: mixed observational and } \\
\text { direct patient questioning } \\
\text { Full tool = } 9 \text { items (requires } \\
\text { coadministration of a brief cognitive } \\
\text { assessment tool) }\end{array}$ & $\begin{array}{l}\text { Moderate rater training required; training manual available at http:// } \\
\text { www.hospitalelderlifeprogram.org/ }\end{array}$ \\
\hline $\begin{array}{l}\text { Nursing Delirium } \\
\text { Screening Scale }(\mathrm{Nu}- \\
\text { DESC) }\end{array}$ & $\begin{array}{l}\text { Nursing: end of each nursing shift } \\
\text { Observational, brief, } 5 \text { items (possible } \\
\text { range of total score } 0-10 \text { ) } \\
\text { Symptoms rated from } 0 \text { to } 2 \text { based on } \\
\text { presence and intensity of each symptom } \\
\text { A total score of } \geq 2 \text { should prompt further } \\
\text { evaluation with CAM }\end{array}$ & $\begin{array}{l}\text { Some training required; lower sensitivity for detection of hypoactive } \\
\text { delirium; no published formal validation study in palliative care } \\
\text { patients }\end{array}$ \\
\hline $\begin{array}{l}\text { Delirium Observation } \\
\text { Screening (DOS) } \\
\text { Scale }\end{array}$ & $\begin{array}{l}\text { Nursing: end of each nursing shift } \\
\text { Observational, } 13 \text { items (possible range of } \\
\text { total score } 0-13 \text { ) } \\
\text { Score of } \geq 3 \text { indicates delirium }\end{array}$ & Some training required; validated in palliative care patients \\
\hline
\end{tabular}

Table 2 Examples of delirium assessment tools (for diagnosis and severity rating) [8, 10, 17, 28, 29]

\begin{tabular}{|c|c|c|}
\hline Tool or criteria & Administration & Comments \\
\hline \multicolumn{3}{|l|}{ Diagnostic criteria } \\
\hline DSM-5 & & High level of training required \\
\hline ICD-10 & & High level of training required \\
\hline \multicolumn{3}{|c|}{ Delirium-specific assessment tools } \\
\hline $\begin{array}{l}\text { Delirium Rating Scale- } \\
\text { revised-98 (DRS-R-98) }\end{array}$ & $\begin{array}{l}\text { 16-item clinician rated scale ( } 13 \text { severity items and } 3 \text { diagnostic } \\
\text { items) } \\
\text { Maximum total score }=46\end{array}$ & $\begin{array}{l}\text { Designed for broad phenomenological } \\
\text { assessment of delirium; manual to guide } \\
\text { rating available }\end{array}$ \\
\hline $\begin{array}{l}\text { Memorial Delirium } \\
\text { Assessment Scale (MDAS) }\end{array}$ & $\begin{array}{l}\text { 10-item clinician-rated scale (possible range of total score } 0-30 \text { ); } \\
\text { originally designed for administration by psychiatrists to assess } \\
\text { delirium severity; diagnostic cutoff score of } 7 \text { (was } 13 / 30 \text { in } \\
\text { original study) }\end{array}$ & $\begin{array}{l}\text { Training required } \\
\text { Validated in palliative care patients } \\
\text { Can pro-rate scores }\end{array}$ \\
\hline $\begin{array}{l}\text { Confusion Assessment } \\
\text { Method (CAM) diagnostic } \\
\text { algorithm }\end{array}$ & $\begin{array}{l}\text { Brief 4-item tool (requires coadministration of a brief cognitive } \\
\text { assessment tool) }\end{array}$ & Validated in palliative care population \\
\hline
\end{tabular}

DSM-5 Diagnostic and Statistical Manual of Mental Disorders, 5th Edition, ICD-10 International Classification of Diseases, 10th revision

\subsection{Delirium Subtype Classification}

Three clinical subtypes of delirium have been described according to the type of psychomotor activity: hyperactive, hypoactive, and mixed. In palliative care patients, the hypoactive and mixed subtypes are the most common. The hypoactive subtype is often missed [30] as these patients become somnolent and withdrawn with impaired cognition but with no visible agitation, or is misdiagnosed as depression or fatigue especially as patients become frailer. However, patients with hypoactive delirium may also experience perceptual disturbances (e.g., hallucinations) and delusions in addition to experiencing considerable distress and having a poorer prognosis [31-33]. Diagnosing delirium in patients approaching the dying phase, especially the hypoactive subtype, is challenging given patients' reduced level of consciousness and reduced communication as their condition declines.

\section{Pathophysiology of Delirium}

The pathophysiology of delirium is complex and not fully understood. In view of both the multifactorial nature of delirium and multiple disease contexts in which delirium is likely to occur, it is perhaps not surprising that no single unifying theory exists that encompasses its diverse etiologic spectrum. An in-depth review of delirium 
pathophysiology is beyond the scope of this clinically oriented review; the neuropathogenesis of delirium has been comprehensively reviewed elsewhere [34]. Maldonado [34] has identified seven main theories that may, to varying degrees, be used to explain the neuropathogenesis of delirium; he suggests that these mechanistic hypotheses do not so much compete with each other as tend to complement and sometimes overlap each other. These theories relate to various cerebral clinicopathological entities, including neuroinflammation, neuronal aging, oxidative stress, various neurotransmitter alterations, neuroendocrine aberrations, and melatonin dysregulation, in addition to a breakdown in the integration of neuronal networks. More recently, Maldonado [35] has sought to integrate the theory of neurotransmitter dysregulation with the neuronal network dysconnectivity theory in a newly proposed "systems integration failure hypothesis" (SIFH). In the context of palliative care, in which many patients have a cancer diagnosis, the high prevalence of systemic inflammation is a possible contributor in the pathogenesis of delirium [14]. Blood-brain barrier dysfunction in the context of systemic inflammation may result in cytokines and inflammatory mediators crossing into the central nervous system (CNS) and promoting neuroinflammation with consequent delirium $[34,36]$.

The fundamental therapeutic strategy for an episode of delirium entails treating its precipitating factors where possible and targeting its symptomatic distress, if necessary through pharmacological intervention [14]. The mechanism of neurotransmitter imbalance (mostly cholinergic deficiency and/or relative excess of dopaminergic neurotransmission) as a final common pathway has to date largely underpinned the pharmacological approach of antidopaminergic antipsychotic use in the treatment of distressing delirium symptoms [14, 37]. However, the extent of neurotransmitter disturbance in the pathogenesis of delirium is increasingly realized as being much broader and more complex than the dopaminergic-cholinergic imbalance. The most common additional neurotransmission disturbances include excess norepinephrine and/or glutamate; increased or decreased $\gamma$-aminobutyric acid (GABA), $N$-methyl-D-aspartate (NMDA), and 5-hydroxytryptamine (5-HT; serotonin); and decreased melatonin [34]. These disturbances may to varying degrees provide other therapeutic targets for a pharmacologic approach to symptom management [38-41].

\section{Etiologic Considerations}

The etiology of delirium is often viewed as being multifactorial and this is invariably the case in the context of advanced disease in palliative care settings. Inouye and
Charpentier's conceptual framework to describe the etiology of delirium in the elderly highlights the interrelationship between a patient's baseline vulnerability, as reflected by potential predisposing factors such as old age, and superimposed more acute precipitating factors such as infection [42]. This model is readily applicable to delirium in palliative care, where baseline vulnerability relates to factors such as age, frailty, poor nutritional status, impaired functional status, chronic renal impairment, and pre-existing dementia. Precipitating factors for delirium include medications, especially psychoactive types, notably opioids and benzodiazepines; infection; metabolic factors such as organ dysfunction and electrolyte disturbance; hypoxia; and dehydration. Etiologic factors for patients with cancer are summarized in Fig. 3. A prospective study in a tertiarylevel palliative care unit identified a median of three (range 1-6) precipitants per episode of delirium in advanced cancer patients [43]. Similarly, frail geriatric patients have multiple precipitants for acute delirium [44]. Due to the multifactorial nature of delirium in the context of palliative care, the approach to both prevention and treatment accordingly warrant a multicomponent approach [45].

\section{Prevention}

A recent meta-analysis showed that multicomponent nonpharmacological interventions reduce the incidence of delirium by over $40 \%$ for older adult patients (without a terminal illness) in hospital or long-term residential care settings [46]. The 2010 National Institute for Health and Clinical Excellence (NICE) guideline for the prevention of delirium (which excluded dying patients) made 13 recommendations for the prevention of delirium in at-risk adults, and also showed that this approach was cost effective on economic analysis [47]. A multicomponent intervention package can be applied by all members of the interprofessional team, with appropriate training and supportive healthcare system structures. However, at this time, the efficacy and applicability of these approaches for terminally ill patients is not clear [46, 48, 49].

\subsection{Non-Pharmacological Interventions to Prevent Delirium}

In a seminal paper, Inouye et al. [50] reported on a multicomponent intervention for six delirium risk factors (cognitive impairment, sleep deprivation, immobility, visual and hearing impairment, and dehydration) in 852 hospitalized patients $\geq 70$ years of age, which resulted in a significant reduction in both delirium incidence in the intervention group (9.9\% vs. $15 \%$ in the usual care group) and duration of delirium episodes. This model of care was 
Fig. 3 Factors contributing to delirium in cancer patients (adapted from Bush and Bruera [160], with permission from the publisher)

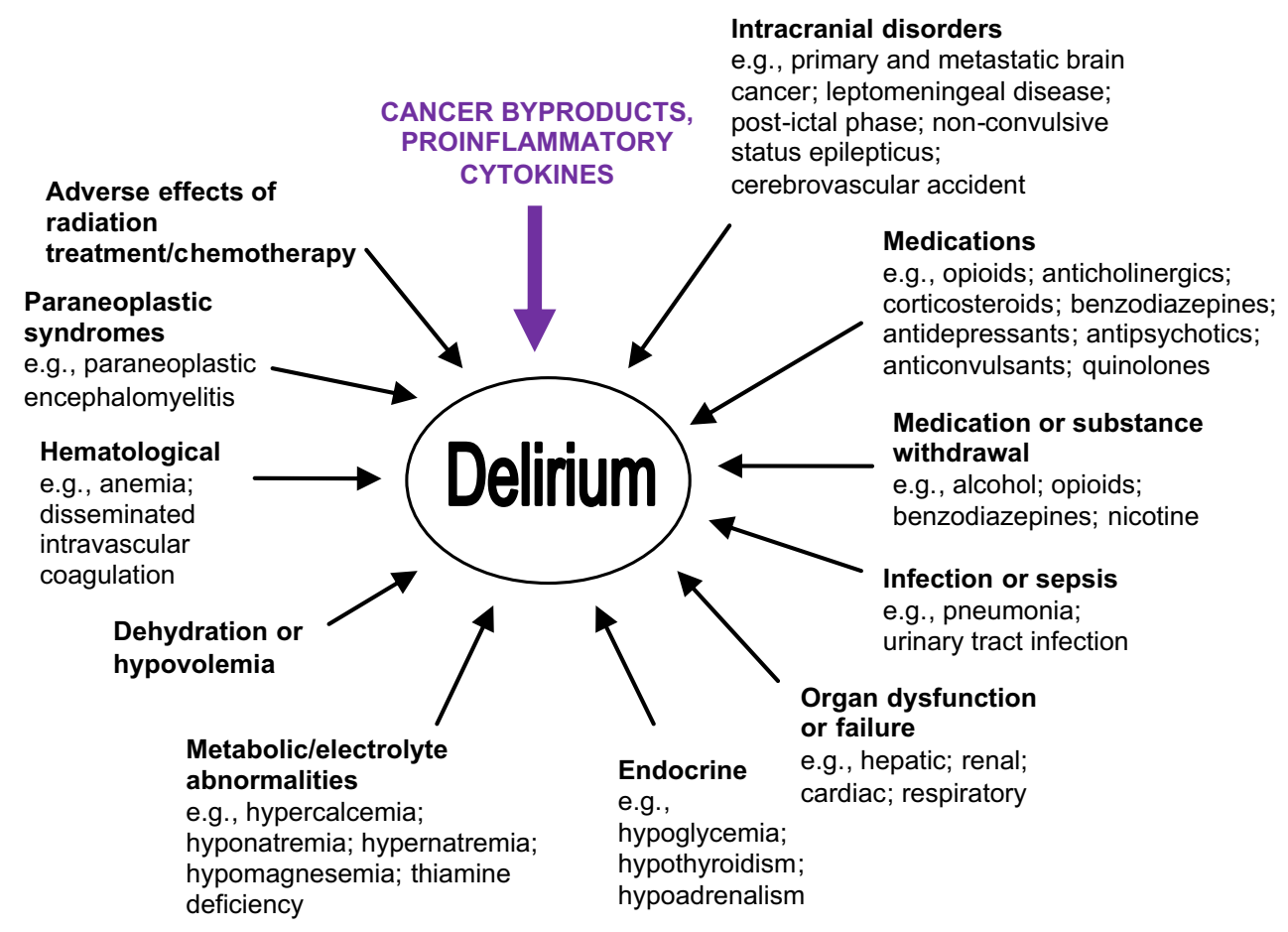

named HELP $[19,51]$. The innovative HELP program for older patients now comprises multiple protocols, including protocols for orientation, therapeutic activities, fluid replacement, early mobilization, feeding assistance, vision, hearing, sleep enhancement, and review of psychoactive medications, and is led by trained volunteers and family members [52]. As part of fundamental clinical practice, clinicians should ensure that patients are hydrated, avoid unnecessary catheterization, optimize sleep hygiene, encourage mobilization, avoid sensory deprivation (with appropriate lighting and use of hearing and visual aids), and use verbal orientation and devices such as a visible clock and orientation board [53]. Another evidence-based strategy for delirium prevention includes comprehensive geriatric assessment in perioperative elderly patients [54]. See Table 3 for non-pharmacological strategies that can be implemented by the healthcare team and family for palliative care patients.

\subsection{Pharmacological Interventions to Prevent Delirium}

A recent Cochrane review [57] found no clear evidence for a reduction in delirium incidence with cholinesterase inhibitors or perioperative antipsychotic medications from randomized controlled trials (RCTs) in hospitalized nonintensive care patients, except for one moderate-quality study comparing perioperative olanzapine with placebo in 400 elderly participants undergoing joint replacement surgery [58]. However, in this study, delirium duration and severity was greater in the olanzapine arm. A double-blind, placebo-controlled randomized trial of low-dose melatonin in 145 elderly internal medicine inpatients reported a reduced risk of delirium: $12 \%$ in melatonin treated group versus $31 \%$ in placebo group $(p=0.014)$ [59]. A recent pilot study of melatonin in 30 advanced cancer inpatients reported a reduced incidence of delirium of $7 \%(1 / 14)$ in the melatonin arm versus $25 \%(4 / 16)$ in the placebo arm [60].

\section{Decision-Making in the Management Approach}

Although delirium complicates the last hours or days of life for most patients in palliative care settings [2], delirium is also characterized by the potential for reversal in certain circumstances, depending on the nature of the precipitant factors and the degree of baseline vulnerability. Antibiotics for infection and bisphosphonates for hypercalcemia are examples of treatable precipitants should such therapeutic interventions be consistent with the patient's goals of care. In palliative care, evidence suggests that approximately $50 \%$ of delirium episodes can be reversed [43], especially those precipitated by medications, infection, and electrolyte abnormalities [43, 61]. However, reversible delirium and irreversible delirium often share a very similar clinical presentation; they may be indistinguishable until basic clinical (laboratory and sometimes radiological) investigations are completed. The apparent paradoxical connotations of delirium, in that it is ominously and almost 
Table 3 Non-pharmacological delirium strategies for palliative care patients $[55,56]$

\begin{tabular}{ll}
\hline Delirium management strategies & Details \\
\hline Optimize sleep-wake pattern & Daytime: increase exposure to daylight. Shades/curtains open \\
& Night-time: reduce light and noise \\
& Familiar sleepwear \\
Patient orientation & Reorientate person: explain where they are, who they are, who you are and your role \\
& Complete orientation whiteboard, visible clock \\
Communication & Avoid frequent room changes \\
Encourage mobility & Use eye glasses, hearing aids, and dentures where needed \\
& Mobilize as patient's performance status allows \\
& Sit out of bed for meals if possible \\
& Avoid using physical restraints \\
Minimize use of immobilizing urinary catheters & Encourage patient to drink, if able to swallow safely \\
Monitor hydration and nutrition & Assist patient at mealtimes \\
Monitor bladder and bowel function & Assess for urinary retention, constipation, and fecal impaction. Avoid unnecessary \\
catheterization & Reassure patient with calming voice \\
Provide support and education & Use delirium information leaflet \\
\end{tabular}

inextricably linked with the terminal phase on the one hand and displays reversibility on the other (albeit perhaps earlier in the disease trajectory, but yet within the context of end of life, as we have defined it in this review) generates challenges for clinicians, patients, and their substitute decision makers (SDMs). These challenges and the patient's goals of care may combine to generate a decisional dilemma.

The underpinnings of this dilemma relate to the risk of being unduly fatalistic (assuming irreversibility of delirium; failure to investigate clinically; and missing potentially reversible delirium precipitants) and using continuous deep (palliative) sedation inadvertently as a premature option. Death in this context becomes a selffulfilling prophecy. Alternatively, there is the risk of adopting an overly aggressive medicalized approach that could involve inappropriately burdensome and non-costeffective investigations and treatments in a truly non-reversible episode of delirium. Ultimately, the clinical outcome of delirium may therefore be strongly influenced by the management approach.

The ideal management decision-making process requires an individualized approach and clear, sensitive communication with family or other SDMs is imperative, as the patient will most often lack decisional capacity. The factors in the decisional mix will include clarification of the known clinical status; the trajectory of the illness and the suspected or known delirium precipitants; the functional status prior to the episode of delirium; the desire for further investigation, based on the patient's prior expressed goals of care; and the risk and burden of further investigation or treatment. Sometimes a timed trial of antibiotics may be necessary when the outcome of treating an infection (as a delirium precipitant) is difficult to predict. It should be remembered that patients and their families may be hugely appreciative of delirium reversal or part reversal, even for a short period so as to allow some meaningful communication between patient and family.

Regardless of whether clinical investigations are conducted to establish the nature of delirium precipitants or whether therapeutic interventions are pursued to achieve some degree of delirium reversal, the need for symptomatic treatment of delirium will require careful evaluation in the context of either end-of-life or terminal-phase care.

\section{Management of Potentially Reversible Precipitants}

Although approximately $50 \%$ of delirium episodes can be reversed in palliative care patients [43], especially when the precipitants are medications, infection, or hypercalcemia [43, 62], the decision to initiate treatment in an attempt to reverse an underlying cause(s) for delirium is dependent on a patient's estimated prognosis and goals of care. See Sect. 7 for a more in-depth discussion of this clinical challenge.

\subsection{Medication-Induced Delirium}

Medications are an increasingly common precipitant of delirium [63] as well as other neuropsychiatric adverse 
effects, especially in the elderly and other patients with altered pharmacokinetics and pharmacodynamics. Thus, active de-prescribing of deliriogenic medications (e.g., benzodiazepines, antidepressants, antipsychotics, anticonvulsants, corticosteroids, and quinolones) $[64,65]$ is a critical component of delirium management. Currently, the evidence for anticholinergic medications as delirium precipitants is contradictory [66-70]. All patients should have a careful assessment of their current and recent medication profile for potentially deliriogenic medications [71], with consideration of dose taper and/or discontinuation.

\subsubsection{Opioid-Induced Neurotoxicity}

The majority of palliative care patients with end-stage disease will require treatment with opioids for pain and/or dyspnea. Opioid-induced neurotoxicity (OIN) is a syndrome of neuropsychiatric adverse effects that may occur with opioid therapy, and is exacerbated by a large dose, or rapid increase in opioid dose, and dehydration. The features of OIN are severe sedation, cognitive impairment, delirium, hallucinations, myoclonus, seizures, hyperalgesia, and allodynia. OIN is managed by opioid dose reduction if pain is well-controlled, or opioid rotation (also known as opioid 'switch') with an accompanying decrease in the equianalgesic dose of the new opioid by at least onethird because of incomplete cross tolerance [72]. In addition, intravenous or subcutaneous hydration may be utilized.

\subsection{Dehydration}

Clinically assisted hydration may be used in the management of patients with delirium, in particular when dehydration is thought to be a contributing factor. However, in a double-blind placebo-controlled randomized trial in 129 advanced cancer patients, subcutaneous hydration (hypodermoclysis) of $1000 \mathrm{~mL}$ of normal saline did not improve symptoms [73]. Memorial Delirium Assessment Scale (MDAS) scores worsened from baseline, with a non-significant trend for less deterioration in the hydration arm. Further research in this area of clinical practice is needed [74].

\subsection{Hypercalcemia}

In patients with advanced cancer, corrected calcium levels above $3.0 \mathrm{mmol} / \mathrm{L}$ usually cause significant problems, including delirium. Management depends on the severity of symptoms, patient's wishes, and estimated life expectancy, and includes parenteral hydration with saline and treatment with bisphosphonate or calcitonin [75, 76]. The use of subcutaneous denosumab, a monoclonal antibody acting against the receptor activator of nuclear factor- $\kappa \mathrm{B}$ (RANK) ligand, has recently been reported in 33 advanced cancer patients with bisphosphonate-refractory hypercalcemia [77]. In this study, denosumab was found to lower serum calcium levels in 21 of $33(64 \%)$ patients within 10 days [77]. Due to an increased risk of hypocalcemia with denosumab, patients should be monitored post-treatment as they may require calcium and vitamin $\mathrm{D}$ supplementation [78]. Results from larger studies with longer-term evaluation after denosumab treatment are needed.

\subsection{Brain Tumor or Metastasis}

Although corticosteroids themselves have neuropsychiatric effects, including delirium [79], they are often used to reduce peri-tumor edema, e.g., dexamethasone 4-8 mg daily in divided doses. In some patients with primary brain tumors, e.g., patients with progressive symptoms from intracranial glioblastoma multiforme, higher doses of corticosteroids may be required. There may also be a role for palliative radiotherapy depending on the patient's overall condition, burden of treatment, and goals of care.

\section{Pharmacological Management of Delirium in Palliative Care Patients}

Medications, in particular antipsychotics, have been utilized in the routine management of delirium in palliative care despite limited research evidence to support this practice [80]. Table 4 summarizes randomized trials for the management of delirium in non-intensive care populations. The Appendix in the Electronic Supplementary Material provides more in-depth information for medications that have been used in the management of delirium in palliative care. It should be noted that no medication is currently licensed for use in the management of delirium, so the use of medications for the indication of delirium is 'off-label'.

\subsection{Role of Antipsychotics in Delirium Management}

Despite limited RCT evidence [88], antipsychotics are commonly used in the management of delirium [89]. Back in 1993, the first edition of the Oxford Textbook of Palliative Medicine described haloperidol as "the drug of choice in the treatment of delirium in the medically ill" [90]. In 1999, the American Psychiatric Association's comprehensive practice guideline on delirium stated that "antipsychotics have been the medication of choice in the treatment of delirium" [91]. This practice was supported by a neurotransmitter hypothesis for the pathophysiology of delirium with a deficit of acetylcholine and an excess of dopamine for the pathophysiology of delirium, resulting in 


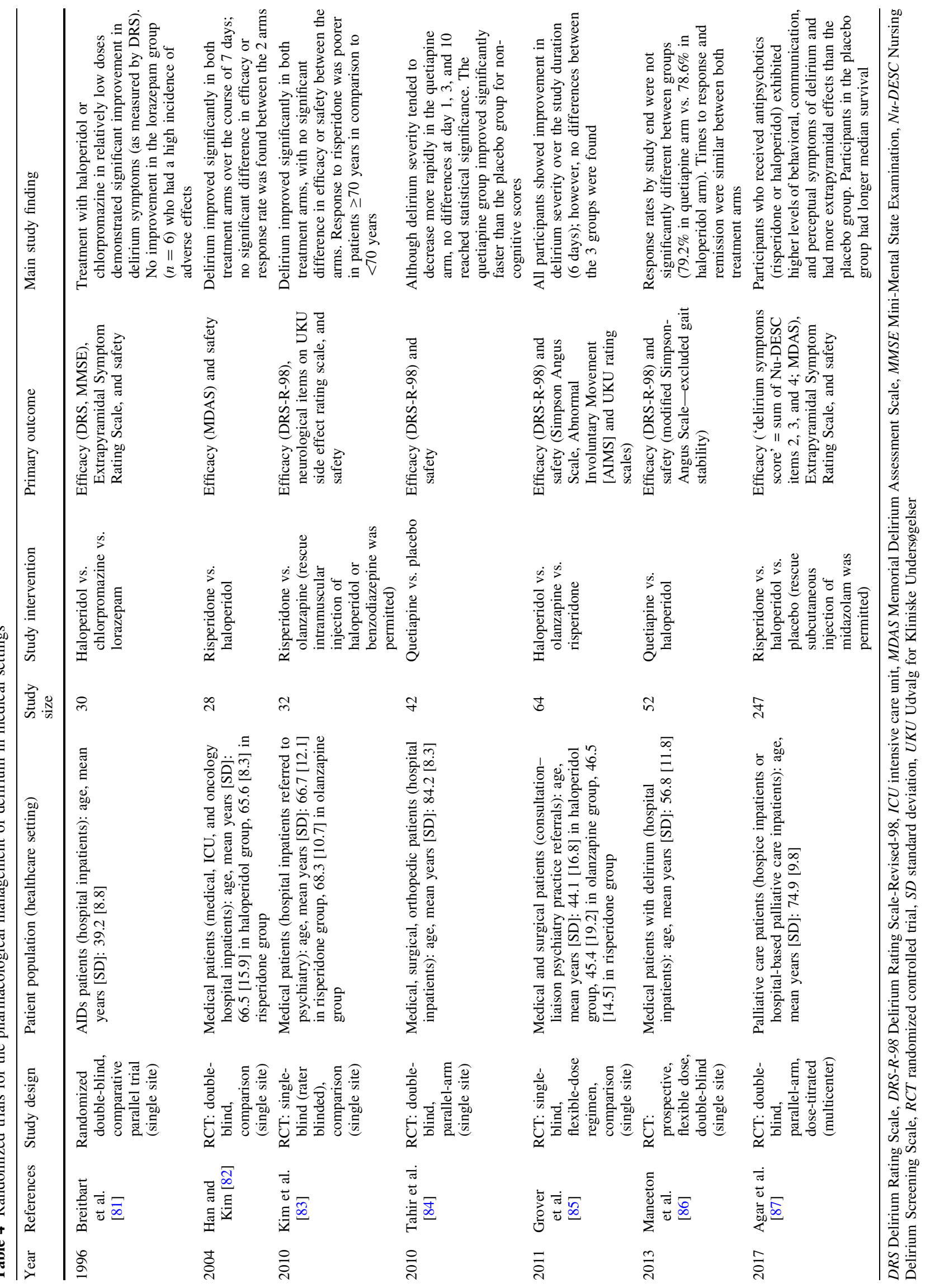


Table 5 Receptor affinities for selected antipsychotics (derived from Procyshyn et al. [92] Howard et al. [93], and Lal et al. [94])

\begin{tabular}{|c|c|c|c|c|c|c|c|}
\hline Drug & $\begin{array}{l}\mathrm{D}_{2} \\
\text { blockade }^{\mathrm{a}}\end{array}$ & $\begin{array}{l}5-\mathrm{HT}_{1 \mathrm{~A}} \\
\text { blockade }\end{array}$ & $\begin{array}{l}5-\mathrm{HT}_{2 \mathrm{~A}} \\
\text { blockade }\end{array}$ & $\begin{array}{l}\alpha_{1} \\
\text { blockade }^{b}\end{array}$ & $\begin{array}{l}\alpha_{2} \\
\text { blockade }\end{array}$ & $\begin{array}{l}\mathrm{H}_{1} \\
\text { blockade }^{\mathrm{c}}\end{array}$ & $\begin{array}{l}\mathrm{M}_{1} \\
\text { blockade }^{\mathrm{d}}\end{array}$ \\
\hline Haloperidol & +++++ & + & +++ & +++ & + & + & + \\
\hline $\begin{array}{l}\text { Levomepromazine } \\
\text { (methotrimeprazine) }\end{array}$ & +++ & $?$ & ++++ & +++++ & ++ & +++++ & ++ \\
\hline Chlorpromazine & ++++ & + & ++++ & ++++ & ++ & +++ & +++ \\
\hline Olanzapine & +++ & + & ++++ & +++ & ++ & ++++ & ++++ \\
\hline Quetiapine & ++ & $++^{\mathrm{e}}$ & +++ & +++ & +++ & +++ & ++ \\
\hline Risperidone & ++++ & ++ & +++++ & ++++ & ++ & +++ & - \\
\hline Aripiprazole & $+++++^{\mathrm{e}}$ & $++++^{\mathrm{e}}$ & ++++ & +++ & +++ & +++ & - \\
\hline
\end{tabular}

The lower the $K_{i}$ value, the higher the receptor affinity

Increased sedation associated with increasing $\mathrm{H}_{1}$ blockade

5- $H T_{1 A}$ 5-hydroxytryptamine-1A (serotonergic) receptor, 5- $H T_{2 A}$ 5-hydroxytryptamine-2A (serotonergic) receptor, $D_{2}$ dopamine-2 receptor, $H_{I}$ histamine- 1 receptor, $K_{i}$ inhibition constant, $M_{1}$ anticholinergic (muscarinic-1) receptor, $\alpha_{1}$ alpha- 1 adrenergic receptor, $\alpha_{2}$ alpha-2 adrenergic receptor, - indicates $K_{i}>10,000 \mathrm{nM},+$ indicates $K_{i} 1000-10,000 \mathrm{nM},++$ indicates $K_{i} 100-1000 \mathrm{nM},+++$ indicates $K_{i} 10-100 \mathrm{nM},++++$ indicates $K_{i} 1-10 \mathrm{nM},+++++$ indicates $K_{i} 0.1-1 \mathrm{nM}$, ? indicates unknown $K_{i}$

${ }^{a}$ Pharmacological effects of antagonism in nigrostriatal system: extrapyramidal side effects partially mitigated in second-generation (atypical) antipsychotics by $5-\mathrm{HT}_{2 \mathrm{~A}}$ receptor antagonism

${ }^{\mathrm{b}}$ Pharmacological effects: postural hypotension, dizziness, sedation

c Pharmacological effects: sedation, anxiolytic effects

${ }^{d}$ Pharmacological effects: moderation of extrapyramidal adverse effects; anticholinergic effects: blurred vision, dry mouth, constipation, etc

e Partial agonist

a "final common pathway" [37], although it is now thought that many different neurotransmitter changes potentially lead to delirium [34].

Antipsychotics are divided into three classes:

1. First generation (previously known as 'typical'):

- Butyrophenones: haloperidol.

- Phenothiazines: e.g., levomepromazine (methotrimeprazine), chlorpromazine, prochlorperazine, promazine.

2. Second generation (previously known as 'atypical'):

- e.g., olanzapine, quetiapine, risperidone, ziprasidone, clozapine

3. Third generation

- e.g., aripiprazole.

Table 5 shows the receptor affinities for antipsychotics commonly used for delirium.

In elderly patients and patients with dementia, the use of first-, second-, and third- generation antipsychotics is associated with an increased risk of death, stroke, and transient ischemic attack [95, 96]. (In the meta-analysis of randomized placebo-controlled trials with atypical antipsychotics by Schneider et al. [96], the duration of included studies ranged from 6 to 26 weeks.) Thus, in patients with co-morbid dementia, the use of antipsychotics should be avoided. If deemed clinically necessary, consider quetiapine if the oral route is possible, as a retrospective study of over 90,000 patients with dementia found the number needed to harm $(\mathrm{NNH})=50$ with quetiapine compared with $\mathrm{NNH}$ $=26$ with haloperidol [97]. For delirious patients who also have Parkinson's disease or dementia with Lewy bodies (DLB), second-generation antipsychotics (e.g., quetiapine) are preferred because first-generation antipsychotics increase the risk of disease exacerbation and extrapyramidal side effects (EPS) in such patients [98]. In these patient groups, alternatives to antipsychotics should also be considered, such as a benzodiazepine for agitation.

Haloperidol has been the 'practice standard' antipsychotic for delirium management in palliative care for many years, in part due to familiarity with its use in clinical practice, the versatility of multiple routes of administration, especially the subcutaneous route, and the absence of placebo-controlled trial evidence prior to a recent study by Agar et al. [87] (see below). The use of haloperidol may also be derived from emergency psychiatric services where haloperidol combined with a benzodiazepine or promethazine is used in the management of psychosis-induced aggression for rapid tranquilization [99]. Haloperidol is predominantly metabolized by the liver; its metabolites include reduced haloperidol, an active metabolite, as well 


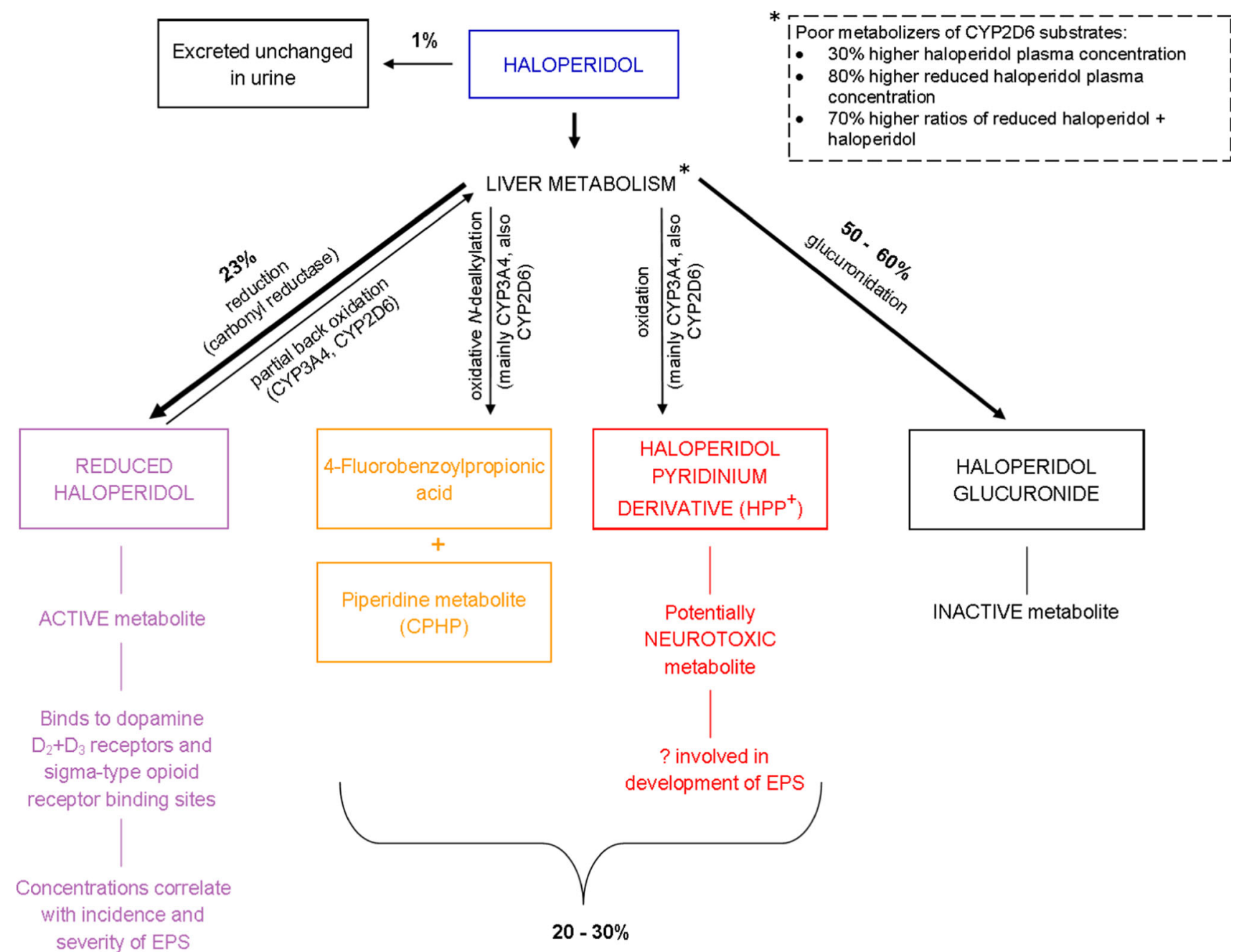

Fig. 4 Metabolism of haloperidol [100-102] (note large interindividual variations in haloperidol pharmacokinetics). CPHP 4-(4-chlorophenyl)4-hydroxypiperidine, CYP cytochrome P450, EPS extrapyramidal side effects

as a potentially neurotoxic pyridinium metabolite [100]. Figure 4 shows the metabolism of haloperidol.

Small observational studies in cancer patients have compared haloperidol, risperidone, and olanzapine with aripiprazole ( $n=21$, case-matched) [103] or with quetiapine $(n=27)$ [104] with improvement in MDAS scores, but more EPS reported with haloperidol. In some countries, levomepromazine (methotrimeprazine) or chlorpromazine are used for symptomatic relief of agitated delirium due to their sedative effect [105-107].

In 2012, a Cochrane review for drug therapy for delirium in terminally ill adult patients concluded that "there remains insufficient evidence to draw conclusions about the role of drug therapy" [108]. The NICE-commissioned Clinical Guideline 103 on delirium recommended a limited role for antipsychotics: "If a person with delirium is distressed or considered a risk to themselves or others ... consider giving short-term haloperidol or olanzapine" (recommendation 1.6.4) [56]. It should be noted that this comprehensive NICE guideline excluded "people receiving end-of-life care", defined as "last few days of their life" [56]. Increasingly, authors have described potential concerns and harms with antipsychotics [109, 110], as well as confirming a lack of evidence in recent systematic reviews and meta-analysis for the use of haloperidol and other antipsychotics in the use of delirium treatment or prevention in hospitalized adults [111, 112].

Challenging this historical dogma of antipsychotic use for delirium management in palliative care, Agar et al. [87] recently published the results of an Australian multi-site, double-blind, parallel-arm, dose-titrated RCT of oral risperidone, haloperidol, or placebo with rescue subcutaneous midazolam for delirium management in the first reported adequately powered RCT in a palliative care population. Adult inpatients receiving hospice or palliative care with confirmed delirium $(n=247)$ received oral study 
medications over a 72-h period. (There was also an option to continue the blinded study medication for an additional $48 \mathrm{~h}$ if a partial response occurred or to allow a dose taper with symptom resolution.) Study participants had mild to moderate delirium (median baseline MDAS scores ranged from 13.7 to 15.1$)$, and were predominantly male (65.6\%) with a mean age of 74.9 years. The majority had a cancer diagnosis (88.3\%) and baseline Australia-modified Karnofsky Performance Status (AKPS) scores ranged from $30 \%$ to $50 \%$. Participants were randomly assigned risperidone, haloperidol, or placebo as oral solutions. The antipsychotic dosing schedule was the same for both haloperidol and risperidone, and adjusted for age. For participants $\leq 65$ years, a $0.5 \mathrm{mg}$ loading dose was administered along with a first dose of $0.5 \mathrm{mg}$, followed by $0.5 \mathrm{mg}$ every $12 \mathrm{~h}$. If the sum of Nursing Delirium Screening Scale (Nu-DESC) scores (items 2, 3, and 4-for "inappropriate behavior, inappropriate communication and illusions or hallucinations": range $0-6$ ) was $\geq 1$ at the most recent assessment, the dose could be titrated by $0.25 \mathrm{mg}$ on day 1 , and then by $0.5 \mathrm{mg}$ to a maximum dose of $4 \mathrm{mg} /$ day. For participants $>65$ years, the loading, first, and maximum doses were $50 \%$ of the aforementioned doses. The placebo solution was similarly titrated using matching volumes of solution. Doses were reduced if adverse effects, delirium resolution (defined as MDAS score $<7$ for $48 \mathrm{~h}$ ), or resolution of symptoms (sum of $\mathrm{Nu}$ DESC scores $<1$ for $48 \mathrm{~h}$ ) occurred. Subcutaneous 'rescue' midazolam (not age adjusted) was given in a dose of $2.5 \mathrm{mg}$ every $2 \mathrm{~h}$ as needed. All study participants also received treatment of their reversible delirium participants where clinically indicated and non-pharmacological management approaches, consisting of hydration, vision and hearing aids, family presence, and reorientation, "as appropriate". The two main study comparisons were placebo versus risperidone and placebo versus haloperidol. In the intention-to-treat analysis, participants in the risperidone and haloperidol arms had higher delirium symptom scores ( $p=0.02$ and $p=0.009$, respectively) than the placebo arm at study end. In addition, significantly less rescue midazolam was used in the placebo arm. There were statistically significant greater mean extrapyramidal symptoms (as assessed by the Extrapyramidal Symptom Rating Scale) in both active arms than in the placebo arm. Median survival was 26 days in the placebo arm, 17 days in the risperidone arm, and 16 days in the haloperidol arm. In a post hoc analysis of this RCT, the authors reported that participants receiving an antipsychotic were approximately 1.5 times more likely to die. The results of this RCT confirm the importance of maximizing non-pharmacological strategies and reversing delirium precipitants, if appropriate, in patients with delirium of mild to moderate severity. However, further research is required in the management of palliative care patients with severe delirium, or with reduced performance status and increased frailty.

\subsection{Adverse Effects of Antipsychotics}

Due to their variation in receptor affinities, antipsychotics vary in their propensity for extrapyramidal, sedative, anticholinergic, and hypotensive side effects (see Table 6). Cardiac adverse effects include prolongation of the ratecorrected QT (QTc) interval and arrhythmias. As only short-term use of antipsychotics may be used in the management of delirium, the longer-term adverse effects of antipsychotics, such as endocrine and metabolic adverse effects, are not discussed here.

Table 6 Profile of adverse effects for selected antipsychotics at therapeutic doses (derived from Procyshyn et al. [92])

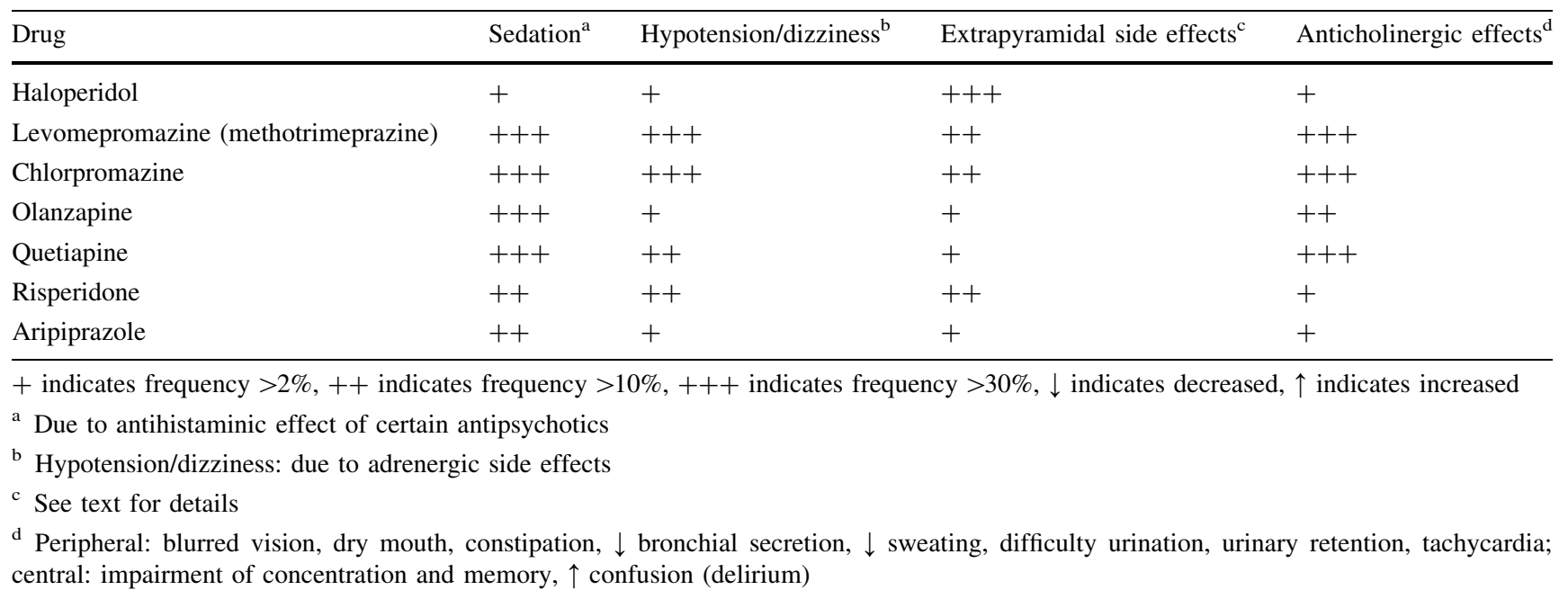




\subsubsection{Extrapyramidal Side Effects}

EPS comprise dystonia, akathisia, parkinsonism, and tardive dyskinesia. While antipsychotic effects are associated with striatal dopamine $\mathrm{D}_{2}$ receptor occupancy of $65-70 \%$, there is a significantly increased risk of EPS when the receptor occupancy is in the range of $80 \%$ or higher [113]. Other risk factors for EPS include high or rapidly increasing antipsychotic dose, especially during the first days of treatment, increasing age, and dementia. There is a reduced risk of EPS with second-generation antipsychotics due to $5-\mathrm{HT}_{2}$ antagonism and $\mathrm{D}_{2}$ partial agonism (quetiapine has the lowest risk). However, EPS can occur at higher doses, especially risperidone $>6 \mathrm{mg} /$ day [106]. There is a reduced tendency to develop antipsychotic-induced parkinsonism with antipsychotics that have anticholinergic activity [114], such as levomepromazine (methotrimeprazine) and quetiapine, as compared with other antipsychotics in their respective classes with less anticholinergic activity.

\subsubsection{Seizures}

Antipsychotics may lower the seizure threshold, and should be used with caution in patients with a seizure history. The risk approximates to the degree of antipsychotic sedation and is dose dependent. Haloperidol is the lowest-risk antipsychotic, and there is a lower likelihood with secondgeneration antipsychotics. The highest risk of precipitating seizures is with sedating antipsychotics, e.g., levomepromazine (methotrimeprazine) and chlorpromazine [93].

\subsubsection{Neuroleptic Malignant Syndrome}

Neuroleptic (antipsychotic) malignant syndrome (NMS) is precipitated by dopamine antagonists. It is an infrequent, idiosyncratic, and potentially fatal syndrome that occurs in $<1 \%$ of patients prescribed an antipsychotic. The clinical features of severe rigidity, hyperthermia, altered mental status, and autonomic dysfunction develop over daysweeks. Hyporeflexia also occurs. Management includes stopping the causative drug and general supportive care. Benzodiazepines may reduce muscle rigidity. Bromocriptine has been used in severe cases, and intravenous dantrolene in acute medical settings [115]. Antipsychotics should not be prescribed for patients who have recovered from NMS as they have a $30-50 \%$ risk of recurrence.

\subsubsection{Corrected QT Interval Prolongation}

An increased risk of sudden cardiac death can occur in users of both first-generation and second-generation antipsychotics [116]. Some antipsychotics have a higher propensity for prolongation of the QTc interval, e.g., thioridazine (drug withdrawn from Canada and other countries) and ziprasidone [117]. With QTc prolongation, especially $>500 \mathrm{~ms}$, patients are at risk of developing 'torsades de pointes' (polymorphic ventricular tachycardia). In addition to antipsychotic dose, risk for drug-induced QTc prolongation may be increased with the presence of other risk factors such as electrolyte abnormality (e.g., hypokalemia, hypomagnesemia, hypocalcemia), drug interaction with the concurrent use of another QT-prolonging medication, congenital long QT syndrome, bradycardia, female sex, and age $>65$ years [118, 119] (a list of QT-prolonging drugs and drug interactions can be found online [120]). An electrocardiogram should be considered in patients with a cardiac history and prolonged dosing of antipsychotic, but in a very distressed delirious palliative care patient the need for antipsychotic administration for symptomatic management may outweigh the potential risk of QTc interval prolongation.

\subsection{Role of Benzodiazepines in Delirium Management}

Palliative care practitioners have been cautious in prescribing benzodiazepines in their patients due to concerns for causing and/or exacerbating delirium. A systematic review examining the association between multiple medication classes and delirium concluded that benzodiazepines may be associated with an increased risk of developing delirium [odds ratio (OR) 3, 95\% confidence interval (CI) 1.3-6.8] using matched analysis data from one moderatequality case-control study of 1341 mixed surgical group patients [67]. In particular, longer-acting benzodiazepines and higher doses of benzodiazepines within a 24-h period increased the risk of delirium. Benzodiazepines are used as first-line agents in the management of alcohol or sedativehypnotic withdrawal. Benzodiazepines may be utilized in agitated patients with Parkinson's disease or DLB because of the risk of EPS with antipsychotics (see ESM Appendix).

In 1996, Breitbart et al. [81] conducted a seminal study in 30 hospitalized AIDS patients with delirium. There was no placebo control group in this randomized, double-blind comparison trial of haloperidol, chlorpromazine, and lorazepam. The lorazepam arm was stopped early as all six patients who received lorazepam either refused to take the drug or had the treatment discontinued due to the development of adverse effects (including over-sedation, disinhibition, ataxia, and increased confusion). In a cohort study of 261 hospitalized cancer patients, patients who received a benzodiazepine dose (assessed as cumulative daily equivalent dose of oral lorazepam) of $>2 \mathrm{mg}$ /day had a two times increased risk of developing delirium (as assessed by 
the $\mathrm{Nu}$-DESC) compared with patients exposed to lower doses [66].

Recently, Ferraz Gonçalves and colleagues [121] reported that a protocol of combined haloperidol and midazolam by the intramuscular or subcutaneous route was significantly more effective than haloperidol alone for agitated palliative care inpatients, with "cognitive impairment as assessed by the Short Confusion Assessment Method". It should be noted that the use of nonpharmacological approaches in the inpatient palliative care unit was not reported as part of their protocol. Further studies are required to better define the role of benzodiazepines in the management of severe agitated delirium.

\subsection{Other Medications Used for Treatment of Delirium}

Other medications that have been examined for a potential role in delirium treatment include methylphenidate, modafinil, valproic acid, gabapentin, ondansetron, and melatonin $[14,106,122]$. They are not currently recommended for routine clinical practice due to limited evidence. A recent systematic review found a lack of efficacy of acetylcholinesterase inhibitors for treating or preventing delirium in older adults, in addition to increased mortality in a prematurely terminated study with rivastigmine [123, 124]. Dexmedetomidine, an $\alpha_{2}$-receptor agonist with analgesic and opioid-sparing properties used for sedation in intensive care settings by intravenous infusion, may potentially have a role in the management of delirium in palliative care patients $[125,126]$.

\section{Delirium Clinical Practice Guidelines}

Few published current delirium clinical guidelines are aimed for patients at the end of life [127]. Delirium guidelines are often limited in their ability to make strong formal recommendations due to the relative lack of high-quality research at this time, resulting in some recommendations for certain guidelines being derived from expert consensus-based statements [128]. However, by identifying the knowledge gaps, guidelines may assist in the prioritization of research activities [129]. Another challenge for guidelines in general is that their content needs to be regularly updated to ensure that current research knowledge is reflected and optimally translated into clinical practice. Appropriate implementation strategies and sustainability plans for guidelines are crucial, as guidelines alone may not improve clinical outcomes [130].

\subsection{Quality Improvement in Delirium Care}

Although not specific to palliative care, the following nonexhaustive list of resources offers useful quality improvement recommendations that can be implemented by the interprofessional team to actively improve delirium care. NICE quality standard 63 recommends five key priorities to improve delirium care [131]. Similarly, the Australian Commission on Safety and Quality in Health Care has recently published a Delirium Clinical Care Standard following on from its initiative entitled "A Better Way to Care: Safe and High-Quality Care for Patients with Cognitive Impairment (Dementia and Delirium) in Hospital" [132]. The Canadian Patient Safety Institute has developed a Safer Healthcare Now!: Prevention and Management of Delirium: "Getting Started Kit" intervention for the prevention and management of delirium [133].

\section{Palliative Sedation}

The development of delirium in dying patients is a poor prognostic sign [134]. The management of refractory agitated delirium (and/or other distressing and refractory symptoms) at the end of life may require the judicious use of proportionate sedative medication to reduce patient distress [135, 136]. By facilitating a more 'peaceful' death with appropriate sedation, family distress will also be relieved.

\subsection{Definition of Palliative Sedation}

Palliative sedation (PS), or sedation in the terminal phase, has been defined as "the intentional administration of sedative drugs in dosages and combinations required to reduce the consciousness of a terminal patient as much as necessary to adequately relieve 1 or more refractory symptoms" [137]. Continuous PS should only be considered when death is anticipated within 2 weeks or less [138]. Appropriately titrated PS is an ethically and legally accepted intervention, and does not shorten life [139, 140]. All discussions with the patient and/or family or SDM should be documented and include the indications for initiating PS. During PS, the level of sedation should be regularly monitored using a clinical assessment tool, e.g., Richmond Agitation-Sedation Scale (RASS) [141] or the palliative version, RASS-PAL [142], in addition to the patient's level of comfort or discomfort. Other symptom management medications, e.g., opioids for pain, should be continued. Patients, family members, and the healthcare team may require emotional support, information provision, and have any concerns with PS addressed. 


\subsection{Medications Used for Palliative Sedation}

Various medications are used for PS. Midazolam is the drug of first choice due its rapid onset of action, but the selection of medication will depend on local drug availability, care location, and the indication for PS. Other medications that are used for PS include levomepromazine (methotrimeprazine), chlorpromazine, lorazepam, and phenobarbital [140, 143] (see Table 7 and the ESM Appendix). Propofol, an ultra-fast-acting general anesthetic agent best suited to use in a monitored setting, has been used as a continuous intravenous infusion when standard treatments have failed [144]. Dexmedetomidine has been used as continuous subcutaneous infusion in the management of refractory delirium in a palliative care unit [145]. It should be noted that the use of medications for PS is based on case series and expert opinion, and that evidence regarding efficacy of PS for symptom control remains insufficient at this time $[143,146]$. Further research is needed on the efficacy and harms of different pharmacologic interventions for PS, and determining appropriate dosing and titration strategies.

\section{Education and Support}

Delirium causes considerable distress for patients and their families, as well as professional caregivers [151, 152]. Patients, even those with hypoactive delirium, may experience perceptual disturbances, delusions, disorientation, and feel threatened and anxious [14]. Namba et al. [153] reported that $70 \%$ of 20 bereaved family members expressed distress at observing delirium in their relatives in the last 2 weeks of life, and identified a need for supportive information. Cohen et al. [154] interviewed 37 family caregivers of adult patients with advanced cancer who had recently recovered from an episode of delirium. Family caregivers "who had expected 'confusion' found the experience less distressing" [154]. Family members need support from the healthcare team; this includes advice on how to respond to a delirious patient, non-pharmacological strategies, as well as information about delirium [155]. Psychoeducational interventions that have been reported as beneficial include verbal information and a delirium information leaflet for family members [156, 157] and 'debriefing' patients who have recovered from an episode of delirium [158].

Table 7 Medications commonly used for palliative sedation in the management of refractory agitated delirium within the last 2 weeks of life [140, 147-150]

\begin{tabular}{|c|c|}
\hline Medication & Details \\
\hline $\begin{array}{l}\text { Midazolam (drug of first } \\
\text { choice) }\end{array}$ & $\begin{array}{l}\text { Rapid onset of action } \\
\text { Short half-life } \\
\text { Dose-dependent sedative effect } \\
\text { Administration: } \mathrm{SC} \text { or IV: } \\
\text { Loading dose }(2.5-5 \mathrm{mg}) \text {, then start continuous infusion at lowest effective dose } \\
\text { Titrate by } 0.5-1 \mathrm{mg} / \mathrm{h} \text { increments q } 30 \text { min according to clinical response and depth of sedation required } \\
\text { Up to maximum } 6 \mathrm{mg} / \mathrm{h} \text { as continuous infusion (CSCI/CIVI) }\end{array}$ \\
\hline Lorazepam & $\begin{array}{l}\text { Lorazepam less amenable to rapid titration up or down than midazolam because of its slower pharmacokinetics } \\
\text { Administration: SC or IV; intermittent bolus: } \\
\text { Starting dose: } 0.05 \mathrm{mg} / \mathrm{kg} \mathrm{q} 2-4 \mathrm{~h} \text { when administered by intermittent bolus }\end{array}$ \\
\hline $\begin{array}{l}\text { Levomepromazine } \\
\text { (methotrimeprazine) }\end{array}$ & $\begin{array}{l}\text { Administration: SC or IV (PO, IM) } \\
\text { Loading dose, then } 12.5-25 \mathrm{mg} \mathrm{q} 6-8 \mathrm{~h} \\
\text { Usual maximum } 200 \mathrm{mg} / 24 \mathrm{~h}\end{array}$ \\
\hline Chlorpromazine & $\begin{array}{l}\text { Administration: IV, deep IM, PR (PO) } \\
\text { Starting dose } 12.5 \mathrm{mg} \mathrm{q} 4-12 \mathrm{~h} \text { (slow IV/IM), or 3-5 mg/h CIVI, or } 25-100 \mathrm{mg} \mathrm{q} 4-12 \mathrm{~h} \text { PR (Doses of } \\
25-375 \mathrm{mg} / 24 \mathrm{~h} \text { reported [139]) }\end{array}$ \\
\hline Phenobarbital (phenobarbitone) & $\begin{array}{l}\text { Administration: SC or IV (IM, PR, PO) } \\
\text { Loading bolus: up to } 200 \mathrm{mg} \\
\text { Then regular dosing: up to } 800 \mathrm{mg} / 24 \mathrm{~h} \text { (Doses of up to } 2400 \mathrm{mg} / 24 \mathrm{~h} \text { and } 3400 \mathrm{mg} / 24 \mathrm{~h} \text { reported } \\
{[140,141] \text { ) }}\end{array}$ \\
\hline
\end{tabular}

$C I V I$ continuous intravenous infusion, $C S C I$ continuous subcutaneous infusion, $I M$ intramuscular, $I V$ intravenous, $P O$ by mouth, $P R$ per rectum, $q \mathrm{x} h$ every $x \mathrm{~h}, q \mathrm{x}$ min every $x \min , S C$ subcutaneous 


\section{Conclusion}

Delirium is a diverse and complex 'endpoint' clinical syndrome resulting from potentially a myriad of interconnected pathophysiological mechanisms. Differing treatment strategies are likely required for differing delirium precipitating factors, pathophysiological variables/mechanisms, subtypes and phenomenological differences, and in early palliative care patients as opposed to patients at the 'end of life' or in the 'dying phase'. As delirium management in the context of palliative care focuses more on targeting symptoms rather than simple receptor targeting, further research is needed as to the benefit and efficacy of pharmacotherapy and multicomponent strategies for reducing morbidity and improving quality of life in this patient population. In the meantime, non-pharmacological strategies should be optimized and antipsychotics used judiciously until more high-quality evidence exists to guide practice in delirium management in palliative care across care settings and the illness trajectory.

Acknowledgements The authors would like to thank Research Administrative Assistant Monisha Kabir for her invaluable assistance in the preparation of the manuscript.

\section{Compliance with Ethical Standards}

Conflicts of interest Authors Shirley H. Bush, Sallyanne Tierney, and Peter G. Lawlor have no conflicts of interest to disclose.

Funding No sources of funding were used in the preparation of this narrative review.

Open Access This article is distributed under the terms of the Creative Commons Attribution-NonCommercial 4.0 International License (http://creativecommons.org/licenses/by-nc/4.0/), which permits any noncommercial use, distribution, and reproduction in any medium, provided you give appropriate credit to the original author(s) and the source, provide a link to the Creative Commons license, and indicate if changes were made.

\section{References}

1. Inouye SK, Westendorp RG, Saczynski JS. Delirium in elderly people. Lancet. 2014;383(9920):911-22.

2. Hosie A, Davidson PM, Agar M, Sanderson CR, Phillips J. Delirium prevalence, incidence, and implications for screening in specialist palliative care inpatient settings: a systematic review. Palliat Med. 2013;27(6):486-98.

3. De La Cruz M, Fan J, Yennu S, Tanco K, Shin S, Wu J, et al. The frequency of missed delirium in patients referred to palliative care in a comprehensive cancer center. Support Care Cancer. 2015;23(8):2427-33.

4. Davis DJ, Muniz-Terrera G, Keage HD. Association of delirium with cognitive decline in late life: a neuropathologic study of 3 population-based cohort studies. JAMA Psychiatry. 2017;74(3):244-51.
5. World Health Organisation. WHO definition of palliative care. http://www.who.int/cancer/palliative/definition/en/. Accessed 6 Jan 2017.

6. Hui D, Nooruddin Z, Didwaniya N, Dev R, De La Cruz M, Kim $\mathrm{SH}$, et al. Concepts and definitions for "actively dying," "end of life," "terminally ill," "terminal care," and "transition of care": a systematic review. J Pain Symptom Manag. 2014;47(1):77-89.

7. Kintzel PE, Chase S, Thomas W, Vancamp D, Clements EA. Anticholinergic medications for managing noisy respirations in adult hospice patients. Am J Health Syst Pharm. 2009;66(5):458-64.

8. American Psychiatric Association. Diagnostic and statistical manual of mental disorders, fifth edition (DSM-5). Arlington: American Psychiatric Association; 2013.

9. American Psychiatric Association. Diagnostic and statistical manual of mental disorders, fourth edition, text revision (DSMIV-TR). Washington: American Psychiatric Association; 2000.

10. World Health Organisation. The ICD-10 classification of mental and behavioural disorders: clinical descriptions and diagnostic guidelines, 1992. http://www.who.int/classifications/icd/en/ bluebook.pdf. Accessed 23 Jan 2017.

11. Kerr CW, Donnelly J, Wright S, Luczkiewicz D, McKenzie K, Hang P, et al. Progression of delirium in advanced illness: a multivariate model of caregiver and clinician perspectives. J Palliat Med. 2013;16(7):768-73.

12. Clegg A, Westby M, Young JB. Under-reporting of delirium in the NHS. Age Aging. 2011;40(2):283-6.

13. Steis MR, Fick DM. Are nurses recognizing delirium? A systematic review. J Gerontol Nurs. 2008;34(9):40-8.

14. Lawlor PG, Bush SH. Delirium in patients with cancer: assessment, impact, mechanisms and management. Nat Rev Clin Oncol. 2015;12(2):77-92.

15. Leonard MM, Nekolaichuk C, Meagher DJ, Barnes C, Gaudreau JD, Watanabe S, et al. Practical assessment of delirium in palliative care. J Pain Symptom Manag. 2014;48(2):176-90.

16. Sands MB, Dantoc BP, Hartshorn A, Ryan CJ, Lujic S. Single Question in Delirium (SQiD): testing its efficacy against psychiatrist interview, the Confusion Assessment Method and the Memorial Delirium Assessment Scale. Palliat Med. 2010;24(6):561-5.

17. Inouye SK, Dyck C, Alessi C, Balkin S, Siegal A, Horwitz RI. Clarifying confusion: the confusion assessment method. A new method for detection of delirium. Ann Intern Med. 1990;113(12):941-8.

18. Ryan K, Leonard M, Guerin S, Donnelly S, Conroy M, Meagher D. Validation of the confusion assessment method in the palliative care setting. Palliat Med. 2009;23(1):40-5.

19. Hospital Elder Life Program (HELP). http://www. hospitalelderlifeprogram.org/. Accessed 27 July 2017.

20. Folstein MF, Folstein SE, McHugh PR. "Mini-mental state": a practical method for grading the cognitive state of patients for the clinician. J Psychiatr Res. 1975;12(3):189-98.

21. Katzman R, Brown T, Fuld P, Peck A, Schechter R, Schimmel $\mathrm{H}$. Validation of a short Orientation-Memory-Concentration Test of cognitive impairment. Am J Psychiatry. 1983;140(6):734-9.

22. Marcantonio E, Ngo L, O'Connor M, Jones R, Crane P, Metzger $\mathrm{E}$, et al. 3D-CAM: derivation and validation of a 3-minute diagnostic interview for CAM-defined delirium: a cross-sectional diagnostic test study. Ann Intern Med. 2014;161(8):554-61.

23. Gaudreau JD, Gagnon P, Harel F, Tremblay A, Roy MA. Fast, systematic, and continuous delirium assessment in hospitalized patients: the nursing delirium screening scale. J Pain Symptom Manag. 2005;29(4):368-75. 
24. Schuurmans MJ, Shortridge-Baggett LM, Duursma SA. The Delirium Observation Screening Scale: a screening instrument for delirium. Res Theory Nurs Pract. 2003;17(1):31-50.

25. Lawlor PG, Bush SH. Delirium diagnosis, screening and management. Curr Opin Support Palliat Care. 2014;8(3):286-95.

26. Adamis D, Rooney S, Meagher D, Mulligan O, McCarthy G. A comparison of delirium diagnosis in elderly medical inpatients using the CAM, DRS-R98, DSM-IV and DSM-5 criteria. Int Psychogeriatr. 2015;27(6):883-9.

27. Leonard MM, Agar M, Spiller JA, Davis B, Mohamad MM, Meagher DJ, et al. Delirium diagnostic and classification challenges in palliative care: subsyndromal delirium, comorbid delirium-dementia, and psychomotor subtypes. J Pain Symptom Manag. 2014;48(2):199-214.

28. Trzepacz PT, Mittal D, Torres R, Kanary K, Norton J, Jimerson N. Validation of the Delirium Rating Scale-revised-98: comparison with the delirium rating scale and the cognitive test for delirium. J Neuropsychiatry Clin Neurosci. 2001;13(2):229-42.

29. Breitbart W, Rosenfeld B, Roth A, Smith MJ, Cohen K, Passik $\mathrm{S}$. The memorial delirium assessment scale. J Pain Symptom Manag. 1997;13(3):128-37.

30. Spiller JA, Keen JC. Hypoactive delirium: assessing the extent of the problem for inpatient specialist palliative care. Palliat Med. 2006;20(1):17-23.

31. Boettger S, Breitbart W. Phenomenology of the subtypes of delirium: phenomenological differences between hyperactive and hypoactive delirium. Palliat Support Care. 2011;9(2):129-35.

32. Breitbart W, Gibson C, Tremblay A. The delirium experience: delirium recall and delirium-related distress in hospitalized patients with cancer, their spouses/caregivers, and their nurses. Psychosomatics. 2002;43(3):183-94.

33. Meagher DJ, Leonard M, Donnelly S, Conroy M, Adamis D, Trzepacz PT. A longitudinal study of motor subtypes in delirium: relationship with other phenomenology, etiology, medication exposure and prognosis. $\mathrm{J}$ Psychosom Res. 2011;71(6):395-403.

34. Maldonado JR. Neuropathogenesis of delirium: review of current etiologic theories and common pathways. Am J Geriatr Psychiatry. 2013;21(12):1190-222.

35. Maldonado JR. Acute brain failure: pathophysiology, diagnosis, management, and sequelae of delirium. Crit Care Clin. 2017;33(3):461-519.

36. Cerejeira J, Noqueira V, Luis P, Vaz-Serra A, MukaetovaLadinska EB. The cholinergic system and inflammation: common pathways in delirium pathophysiology. J Am Geriatr Soc. 2012;60(4):669-75.

37. Trzepacz PT. Is there a final common neural pathway in delirium? Focus on acetylcholine and dopamine. Semin Clin Neuropsychiatry. 2000;5(2):132-48.

38. Sher Y, Miller Cramer AC, Ament A, Lolak S, Maldonado JR. Valproic acid for treatment of hyperactive or mixed delirium: rationale and literature review. Psychosomatics. 2015;56(6):615-25.

39. Winegarden J, Carr DB, Bradshaw YS. Intravenous ketamine for rapid opioid dose reduction, reversal of opioid-induced neurotoxicity, and pain control in terminal care: case report and literature review. Pain Med. 2016;17(4):644-9.

40. Hatta K, Kishi Y, Wada K, Takeuchi T, Odawara T, Usui C, et al. Preventive effects of ramelteon on delirium: a randomized placebo-controlled trial. JAMA Psychiatry. 2014;71(4):397-403.

41. Aripiprazole Prommer E. Am J Hosp Palliat Care. 2017;34(2):180-5.

42. Inouye SK, Charpentier PA. Precipitating factors for delirium in hospitalized elderly persons: predictive model and interrelationship with baseline vulnerability. JAMA. 1996;275(11):852-7.

43. Lawlor PG, Gagnon B, Mancini I, Pereira J, Hanson J, SuarezAlmazor M, et al. Occurrence, causes, and outcome of delirium in patients with advanced cancer: a prospective study. Arch Intern Med. 2000;160(6):786-94.

44. Laurila JV, Laakkonen ML, Laurila JV, Timo SE, Reijo TS Predisposing and precipitating factors for delirium in a frail geriatric population. J Psychosom Res. 2008;65(3):249-54.

45. Abraha I, Rimland JM, Trotta F, Pierini V, Cruz-Jentoft A, Soiza R, et al. Non-pharmacological interventions to prevent or treat delirium in older patients: clinical practice recommendations the SENATOR-ONTOP series. J Nutr Health Aging. 2016;20(9):927-36.

46. Hshieh TT, Yue J, Oh E, Puelle M, Dowal S, Travison T, et al. Effectiveness of multicomponent nonpharmacological delirium interventions: a meta-analysis. JAMA Intern Med. 2015;175(4):512-20.

47. O'Mahony R, Murthy L, Akunne A, Young J. Synopsis of the National Institute for Health and Clinical Excellence guideline for prevention of delirium. Ann Intern Med. 2011;154(11):746-51.

48. Gagnon P, Allard P, Gagnon B, Merette C, Tardif F. Delirium prevention in terminal cancer: assessment of a multicomponent intervention. Psychooncology. 2012;21(2):187-94.

49. Reston JT, Schoelles KM. In-facility delirium prevention programs as a patient safety strategy: a systematic review. Ann Intern Med. 2013;158(5 Pt 2):375-80.

50. Inouye SK, Bogardus ST Jr, Charpentier P, Leo-Summers L, Acampora D, Holford T, et al. A multicomponent intervention to prevent delirium in hospitalized older patients. N Engl J Med. 1999;340(9):669-76.

51. Inouye SK, Bogardus SJ, Baker D, Leo-Summers L, Cooney LM Jr. The Hospital Elder Life Program: a model of care to prevent cognitive and functional decline in older hospitalized patients. Hospital Elder Life Program. J Am Geriatr Soc. 2000;48(12):1697-706.

52. Yue J, Tabloski P, Dowal S, Puelle M, Puelle M, Nandan R, et al. NICE to HELP: operationalizing National Institute for Health and Clinical Excellence guidelines to improve clinical practice. J Am Geriatr Soc. 2014;62(4):754-61.

53. Young J, Murthy L, Westby M, Akunne A, O’Mahony R. Diagnosis, prevention, and management of delirium: summary of NICE guidance. BMJ. 2010;341(c3704).

54. Marcantonio ER, Flacker JM, Wright RJ, Resnick NM. Reducing delirium after hip fracture: a randomized trial. J Am Geriatr Soc. 2001;49(5):516-22.

55. Canadian Coalition for Seniors' Mental Health. Guideline on the assessment and treatment of delirium in older adults at the end of life. Toronto: CCSMH; 2010.

56. National Clinical Guideline Centre. Delirium: diagnosis, prevention and management. Clinical Guideline 103. London: National Clinical Guideline Centre (NCGC) - Acute and Chronic Conditions; 2010.

57. Siddiqi N, Harrison JK, Clegg A, Teale EA, Young J, Taylor J, et al. Interventions for preventing delirium in hospitalised nonICU patients. Cochrane Database Syst Rev. 2016;3:CD005563.

58. Larsen KA, Kelly SE, Stern TA, Bode J, Price LL, Hunter DJ, et al. Administration of olanzapine to prevent postoperative delirium in elderly joint-replacement patients: a randomized, controlled trial. Psychosomatics. 2010;51(5):409-18.

59. Al-Aama T, Brymer C, Gutmanis I, Woolmore-Goodwin SM, Esbaugh J, Dasgupta M. Melatonin decreases delirium in elderly patients: a randomized, placebo-controlled trial. Int $\mathrm{J}$ Geriatr Psychiatry. 2011;26(7):687-94. 
60. Agar M, Lawlor P, Ely EW, Lam L, Nikles J, McCaffrey N, et al. Palliative Care Clinical Studies Collaborative. Randomised double blind placebo controlled phase II trial of prolonged release melatonin for prevention of delirium in inpatients with advanced cancer. Palliat Med. 2016;30(6):NP11-2.

61. Leonard M, Raju B, Conroy M, Donnelly S, Trzepacz PT, Saunders J, et al. Reversibility of delirium in terminally ill patients and predicators of mortality. Palliat Med. 2008;22(7):848-54.

62. Morita T, Tei Y, Tsunoda J, Inoue S, Chihara S. Underlying pathologies and their associations with clinical features in terminal delirium of cancer patients. J Pain Symptom Manag. 2001;22(6):997-1006.

63. Lin RY, Heacock LC, Fogel JF. Drug-induced, dementia-associated and non-dementia, non-drug delirium hospitalizations in the United States, 1998-2005. Drugs Aging. 2010;27(1):51-61.

64. Jackson N, Doherty J, Coulter S. Neuropsychiatric complications of commonly used palliative care drugs. Postgrad Med J. 2008;84(989):121-6.

65. Caraceni A. Drug-associated delirium in cancer patients. EJC Suppl. 2013;11(2):233-40.

66. Gaudreau JD, Gagnon P, Harel FO, Roy MA, Tremblay A. Psychoactive medications and risk of delirium in hospitalized cancer patients. J Clin Oncol. 2005;23(27):6712-8.

67. Clegg A, Young JB. Which medications to avoid in people at risk of delirium: a systematic review. Age Ageing. 2011;40(1):23-9.

68. Fox C, Smith T, Maidment I, Chan W-Y, Bua N, Myint PK, et al. Effect of medications with anti-cholinergic properties on cognitive function, delirium, physical function and mortality: a systematic review. Age Ageing. 2014;43(5):604-15.

69. Zimmerman KM, Salow M, Skarf LM, Kostas T, Paquin A, Simone MJ, et al. Increasing anticholinergic burden and delirium in palliative care inpatients. Palliat Med. 2014;28(4):335-41.

70. Plaschke K, Petersen KA, Frankenhauser S, Weigand MA, Kopitz J, Bardenheuer HJ. The impact of plasma cholinergic enzyme activity and other risk factors for the development of delirium in patients receiving palliative care. J Pain Symptom Manag. 2016;52(4):525-32.

71. Bohmdorfer B, Rohleder S, Wawruch M, van der Cammen TJM, Fruhwald T, Jagsch C, et al. DEL-FINE: a new tool for assessing the delirogenic properties of drugs of relevance for European pharmacotherapy. Z Gerontol Geriatr. 2016;49(5):416-22.

72. Indelicato RA, Portenoy RK. Opioid rotation in the management of refractory cancer pain. J Clin Oncol. 2002;20(1):348-52.

73. Bruera E, Hui D, Dalal S, Torres-Vigil I, Trumble J, Roosth J, et al. Parenteral hydration in patients with advanced cancer: a multicenter, double-blind, placebo-controlled randomized trial. J Clin Oncol. 2013;31(1):111-8.

74. Nakajima N, Satake N, Nakaho T. Indications and practice of artificial hydration for terminally ill cancer patients. Curr Opin Support Pall Care. 2014;8(4):358-63.

75. Stewart AF. Clinical practice. Hypercalcemia associated with cancer. N Engl J Med. 2005;352(4):373-9.

76. Delgado-Guay MO, Yennurajalingam S, Bruera E. Delirium with severe symptom expression related to hypercalcemia in a patient with advanced cancer: an interdisciplinary approach to treatment. J Pain Symptom Manag. 2008;36(4):442-9.

77. Hu MI, Glezerman IG, Leboulleux S, Insogna K, Gucalp R, Misiorowski W, et al. Denosumab for treatment of hypercalcemia of malignancy. J Clin Endocrinol Metab. 2014;99(9):3144-52.

78. Body JJ, Niepel D, Tonini G. Hypercalcaemia and hypocalcaemia: finding the balance. Support Care Cancer. 2017;25(5):1639-49.
79. Dubovsky AN, Arvikar S, Stern TA, Axelrod L. The neuropsychiatric complications of glucocorticoid use: steroid psychosis revisited. Psychosomatics. 2012;53(2):103-15.

80. Bush SH, Kanji S, Pereira JL, Davis DHJ, Currow DC, Meagher DJ, et al. Treating an established episode of delirium in palliative care: expert opinion and review of the current evidence base with recommendations for future development. J Pain Symptom Manag. 2014;48(2):231-48.

81. Breitbart W, Marotta R, Platt M, Weisman H, Derevenco M, Grau C, et al. A double-blind trial of haloperidol, chlorpromazine, and lorazepam in the treatment of delirium in hospitalized AIDS patients. Am J Psychiatry. 1996;153(2):231-7.

82. Han CS, Kim YK. A double-blind trial of risperidone and haloperidol for the treatment of delirium. Psychosomatics. 2004;45(4):297-301.

83. Kim SW, Yoo JA, Lee SY, Kim SY, Bae KY, Yang SJ, et al. Risperidone versus olanzapine for the treatment of delirium. Hum Psychopharmacol. 2010;25(4):298-302.

84. Tahir TA, Eeles E, Karapareddy V, Muthuvelu P, Chapple S, Phillips B, et al. A randomized controlled trial of quetiapine versus placebo in the treatment of delirium. J Psychosom Res. 2010;69(5):485-90.

85. Grover S, Kumar V, Chakrabarti S. Comparative efficacy study of haloperidol, olanzapine and risperidone in delirium. J Psychosom Res. 2011;71(4):277-81.

86. Maneeton B, Maneeton N, Srisurapanont M, Chittawatanarat K. Quetiapine versus haloperidol in the treatment of delirium: a double-blind, randomized, controlled trial. Drug Des Devel Ther. 2013;7:657-67.

87. Agar MR, Lawlor PG, Quinn S. Efficacy of oral risperidone, haloperidol, or placebo for symptoms of delirium among patients in palliative care: a randomized clinical trial. JAMA Intern Med. 2017;177(1):34-42.

88. Seitz DP, Gill SS, Van Zyl LT. Antipsychotics in the treatment of delirium: a systematic review. $J$ Clin Psychiatry. 2007;68(1):11-21.

89. Morandi A, Davis D, Taylor JK, Bellelli G, Olofsson B, Kreisel $\mathrm{S}$, et al. Consensus and variations in opinions on delirium care: a survey of European delirium specialists. Int Psychogeriatr. 2013;25(12):2067-75.

90. Doyle D, Hanks GWC, MacDonald N, editors. Oxford textbook of palliative medicine. 1st ed. Oxford: Oxford University Press; 1993.

91. American Psychiatric Association. Practice guideline for the treatment of patients with delirium. Am J Psychiatry. 1999;156(5 Suppl):1-20.

92. Procyshyn RM, Bezchlibnyk-Butler KZ, Jeffries JJ, editors. Clinical handbook of psychotropic drugs. 21st ed. Boston: Hogrefe Publishing; 2015.

93. Howard P, Twycross R, Shuster J, Mihalyo M, Wilcock A. Antipsychotics. J Pain Symptom Manag. 2011;41(5):956-65.

94. Lal S, Nair NPV, Cecyre D, Quirion R. Levomepromazine receptor binding profile in human brain-implications for treatment-resistant schizophrenia. Acta Psychiatr Scand. 1993;87(6):380-3.

95. Wang PS, Schneeweiss S, Avorn J, Fischer MA, Mogun N, Solomon DH, et al. Risk of death in elderly users of conventional vs. atypical antipsychotic medications. N Engl J Med. 2005;353(22):2335-41.

96. Schneider LS, Dagerman KS, Insel P. Risk of death with atypical antipsychotic drug treatment for dementia: meta-analysis of randomized placebo-controlled trials. JAMA. 2005;294(15):1934-43.

97. Maust DT, Kim HM, Seyfried LS, Chiang C, Kavanagh J, Schneider LS, et al. Antipsychotics, other psychotropics and the 
risk of death in patients with dementia: number needed to harm. JAMA Psychiatry. 2015;72(5):438-45.

98. McKeith I, Fairbairn A, Perry R, Thompson P, Perry E. Neuroleptic sensitivity in patients with senile dementia of Lewy body type. BMJ. 1992;305(6855):673-8.

99. Huf G, Alexander J, Gandhi P, Allen MH. Haloperidol plus promethazine for psychosis-induced aggression. Cochrane Database Syst Rev. 2016;11:CD005146.

100. Kudo S, Ishizaki T. Pharmacokinetics of haloperidol. Clin Pharmacokinet. 1999;37(6):435-56.

101. Brockmöller J, Kirchheiner J, Schmider J, Walter S, Sachse C, Müller-Oerlinghausen B, et al. The impact of the CYP2D6 polymorphism on haloperidol pharmacokinetics and on the outcome of haloperidol treatment. Clin Pharmacol Ther. 2002;72:438-52.

102. Vella-Brincat J, Macleod A. Haloperidol in palliative care. Palliat Med. 2004;18:195-201.

103. Boettger S, Jenewein J, Breitbart W. Haloperidol, risperidone, olanzapine and aripiprazole in the management of delirium: a comparison of efficacy, safety, and side effects. Palliat Support Care. 2015;13(4):1079-85.

104. Tanimukai H, Tsujimoto H, Matsuda Y, Tokoro A, Kanemura S, Watanabe M, et al. Novel therapeutic strategies for delirium in patients with cancer: a preliminary study. Am J Hosp Palliat Care. 2016;33(5):456-62.

105. Dietz I, Schmitz A, Lampey I, Schulz C. Evidence for the use of levomepromazine for symptom control in the palliative care setting: a systematic review. BMC Palliat Care. 2013;12:2.

106. Breitbart W, Alici Y. Evidence-based treatment of delirium in patients with cancer. J Clin Oncol. 2012;30(11):1206-14.

107. Shin SH, Hui D, Chisholm G, Kang JH, Allo J, Williams J, et al. Frequency and outcome of neuroleptic rotation in the management of delirium in patients with advanced cancer. Cancer Res Treat. 2015;47(3):399-405.

108. Candy B, Jackson KC, Jones L, Leurent B, Tookman A, King M. Drug therapy for delirium in terminally ill adult patients. Cochrane Database Syst Rev. 2012;11:CD004770.

109. White C, McCann M, Jackson N. First do no harm... Terminal restlessness or drug-induced delirium. J Palliat Med. 2007;10(2):345-51.

110. Inouye SK, Marcantonio ER, Metzger ED. Doing damage in delirium: the hazards of antipsychotic treatment in elderly persons. Lancet Psychiatry. 2014;1(4):312-5.

111. Schrijver EJM, De Graaf K, De Vries OJ, Maier AB, Nanayakkara PWB. Efficacy and safety of haloperidol for inhospital delirium prevention and treatment: a systematic review of current evidence. Eur J Int Med. 2016;27:14-23.

112. Neufeld KJ, Yue J, Robinson TN, Inouye SK, Needham DM. Antipsychotic medication for prevention and treatment of delirium in hospitalized adults: a systematic review and metaanalysis. J Am Geriatr Soc. 2016;64(4):705-14.

113. Miyamoto S, Duncan GE, Marx CE, Lieberman JA. Treatments for schizophrenia: a critical review of pharmacology and mechanisms of action of antipsychotic drugs. Mol Psychiatry. 2005;10(1):79-104

114. Sachdev PS. Neuroleptic-induced movement disorders: an overview. Psychiatr Clin North Am. 2005;28(1):255-74.

115. Katus L, Frucht S. Management of serotonin syndrome and neuroleptic malignant syndrome. Curr Treat Options Neurol. 2016;18(9):1-8.

116. Ray WA, Chung CP, Murray KT, Hall K, Stein CM. Atypical antipsychotic drugs and the risk of sudden cardiac death. N Engl J Med. 2009;360(3):225-35.

117. Wenzel-Seifert K, Wittmann M, Haen E. QTc prolongation by psychotropic drugs and the risk of torsade de pointes. Dtsch Arztebl Int. 2011;108(41):687-93.
118. Roden DM. Drug-induced prolongation of the QT interval. N Engl J Med. 2004;350(10):1013-22.

119. Pickham D, Helfenbein E, Shinn JA, Chan G, Funk M, Weinacker A, et al. High prevalence of corrected QT interval prolongation in acutely ill patients is associated with mortality: results of the QT in Practice (QTIP) Study. Crit Care Med. 2012;40(2):394-9.

120. CredibleMeds ${ }^{\circledR}$. http://www.crediblemeds.org. Accessed 27 July 2017.

121. Ferraz Gonçalves J, Almeida A, Costa I, Silva P, Carneiro R. Comparison of haloperidol alone and in combination with midazolam for the treatment of acute agitation in an inpatient palliative care service. J Pain Palliat Care Pharmacother. 2016;30(4):284-8.

122. Sher Y, Miller AC, Lolak S, Ament A, Maldonado JR. Adjunctive valproic acid in management-refractory hyperactive delirium: a case series and rationale. J Neuropsychiatry Clin Neurosci. 2015;27(4):365-70.

123. Tampi RR, Tampi DJ, Ghori AK. Acetylcholinesterase inhibitors for delirium in older adults. Am J Alzheimers Dis Other Demen. 2016;31(4):305-10.

124. van Eijk MM, Roes KC, Honing ML, Kuiper MA, Karakus A, van der Jagt $\mathrm{M}$, et al. Effect of rivastigmine as an adjunct to usual care with haloperidol on duration of delirium and mortality in critically ill patients: a multicentre, double-blind, placebo-controlled randomised trial. Lancet. 2010;376(9755):1829-37.

125. Keating GM. Dexmedetomidine: a review of its use for sedation in the intensive care setting. Drugs. 2015;75(10):1119-30.

126. Prommer E. Review article: dexmedetomidine: does it have potential in palliative medicine? Am J Hosp Palliat Care. 2011;28(4):276-83.

127. Bush SH, Marchington KL, Agar M, Davis DH, Sikora L, Tsang TW. Quality of clinical practice guidelines in delirium: a systematic appraisal. BMJ Open. 2017;7(3):e013809. doi:10.1136/ bmjopen-2016-013809.

128. Bush SH, Bruera E, Lawlor PG, Kanji S, Davis DH, Agar M, et al. Clinical practice guidelines for delirium management: potential application in palliative care. J Pain Symptom Manag. 2014;48(2):249-58.

129. Davis D, Goldman J, Palda V. Handbook on clinical practice guidelines. Ottawa: Canadian Medical Association; 2007.

130. Young LJ, George J. Do guidelines improve the process and outcomes of care in delirium? Age Ageing. 2003;32(5):525-8.

131. National Institute for Health and Care Excellence (NICE). Delirium in adults: quality standard [QS63], 2014. http:// guidance.nice.org.uk/qs63. Accessed 27 Jul 2017.

132. Australian Commission on Safety and Quality in Health Care. Delirium clinical care standard, 2016. http://www. safetyandquality.gov.au. Accessed 27 Jul 2017.

133. Canadian Patient Safety Institute (CPSI). Safer healthcare now!: prevention and management of delirium: getting started kit, 2013. http://www.saferhealthcarenow.ca. Accessed 27 July 2017.

134. Breitbart W, Alici Y. Agitation and delirium at the end of life: "we couldn't manage him". JAMA. 2008;300(24):2898.

135. Lo B, Rubenfeld G. Palliative sedation in dying patients: "we turn to it when everything else hasn't worked". JAMA. 2005;294(14):1810-6.

136. Bush SH, Leonard MM, Agar M, Spiller JA, Hosie A, Wright DK, et al. End-of-life delirium: issues regarding recognition, optimal management and the role of sedation in the dying phase. J Pain Symptom Manag. 2014;48(2):215-30.

137. Claessens P, Menten J, Schotsmans P, Broeckaert B. Palliative sedation: a review of the research literature. J Pain Symptom Manag. 2008;36(3):310-33. 
138. Dean MM, Cellarius V, Henry B, Oneschuk D, Librach SL, Canadian Society of Palliative Care Physicians Taskforce. Framework for continuous palliative sedation therapy in Canada. J Palliat Med. 2012;15(8):870-9.

139. Henry B. A systematic literature review on the ethics of palliative sedation: an update (2016). Curr Opin Support Pall Care. 2016;10(3):201-7.

140. Maltoni M, Scarpi E, Rosati M, Derni S, Fabbri L, Martini F, et al. Palliative sedation in end-of-life care and survival: a systematic review. J Clin Oncol. 2012;30(12):1378-83.

141. Sessler CN, Gosnell MS, Grap MJ, Brophy GM, O’Neal PV, Keane KA, et al. The richmond agitation-sedation scale. Am J Respir Crit Care Med. 2002;166(10):1338-44.

142. Bush SH, Grassau PA, Yarmo MN, Zhang T, Zinkie SJ, Pereira JL. The Richmond Agitation-Sedation Scale modified for palliative care inpatients (RASS-PAL): a pilot study exploring validity and feasibility in clinical practice. BMC Palliat Care. 2014;13(1): 17

143. Cherny NI. ESMO Clinical Practice Guidelines for the management of refractory symptoms at the end of life and the use of palliative sedation. Ann Oncol. 2014;25(suppl 3):iii143-52.

144. Lundström S, Zachrisson U, Fürst CJ. When nothing helps: propofol as sedative and antiemetic in palliative cancer care. J Pain Symptom Manag. 2005;30(6):570-7.

145. Hilliard N, Brown S, Mitchinson S. A case report of dexmedetomidine used to treat intractable pain and delirium in a tertiary palliative care unit. Palliat Med. 2014;29(3):278-81.

146. Beller EM, van Driel ML, McGregor L, Truong S, Mitchell G. Palliative pharmacological sedation for terminally ill adults. Cochrane Database Syst Rev. 2015;1:CD010206.

147. Cherny NI, Radbruch L. European Association for Palliative Care (EAPC) recommended framework for the use of sedation in palliative care. Palliat Med. 2009;23(7):581-93.

148. Caraceni A, Zecca E, Martini C, Gorni G, Campa T, Brunelli C, et al. Palliative sedation at the end of life at a tertiary cancer center. Support Care Cancer. 2012;20(6):1299-307.

149. Stirling LC, Kurowska A, Tookman A. The use of phenobarbitone in the management of agitation and seizures at the end of life. J Palliat Care. 1999;17(5):363-8.
150. Gillon S, Johnson M, Campbell C. Review of phenobarbitone use for deep terminal sedation in a UK hospice. Palliat Med. 2009;24(1):100-1.

151. Breitbart W, Gibson C, Tremblay A. The delirium experience: delirium recall and delirium-related distress in hospitalized patients with cancer, their spouses/caregivers, and their nurses. Psychosomatics. 2002;43(3):183-94.

152. Bruera E, Bush SH, Willey J, Paraskevopoulos T, Li Z, Palmer $\mathrm{JL}$, et al. Impact of delirium and recall on the level of distress in patients with advanced cancer and their family caregivers. Cancer. 2009;115(9):2004-12.

153. Namba M, Morita T, Imura C, Kiyohara E, Ishikawa S, Hirai K. Terminal delirium: families' experience. Palliat Med. 2007;21(7):587-94.

154. Cohen MZ, Pace EA, Kaur G, Bruera E. Delirium in advanced cancer leading to distress in patients and family caregivers. Palliat Care. 2009;25(3):164-71.

155. Finucane AM, Lugton J, Kennedy C, Spiller JA. The experiences of caregivers of patients with delirium, and their role in its management in palliative care settings: an integrative literature review. Psychooncology. 2017;26(3):291-300.

156. Gagnon P, Charbonneau C, Allard P, Soulard C, Dumont S, Fillion L. Delirium in advanced cancer: a psychoeducational intervention for family caregivers. $\mathrm{J}$ Palliat Care. 2002;18(4):253-61.

157. Otani H, Morita T, Uno S, Yamamoto R, Hirose H, Matsubara $\mathrm{T}$, et al. Usefulness of the leaflet-based intervention for family members of terminally ill cancer patients with delirium. J Palliat Med. 2013;16(4):419-22.

158. Partridge JS, Martin FC, Harari D, Dhesi JK. The delirium experience: what is the effect on patients, relatives and staff and what can be done to modify this? Int J Geriatr Psychiatry. 2013;28(8):804-12.

159. Canadian Hospice Palliative Care Association. A model to guide hospice palliative care. Ottawa: Canadian Hospice Palliative Care Association; 2002.

160. Bush SH, Bruera E. The assessment and management of delirium in cancer patients. Oncologist. 2009;14(10):1039-49. 